\title{
Understanding the Macroeconomic Impact of Illiquidity Shocks in the US
}

\author{
Chia-Yi Yen* Yu-Hsi Chou ${ }^{\ddagger}$
}

\begin{abstract}
In this paper, we empirically investigate the role of stock market illiquidity shocks, stemming from Amihud (2002)'s illiquidity measure, in explaining US macroeconomic fluctuations from 1973 to 2018 . We find that the impact of illiquidity shocks on economic activity is substantial, and historical decomposition analysis shows that cumulative illiquidity shocks were an essential contributor to the prolonged economic slump of the Great Recession. Moreover, our identified illiquidity shocks represent a distinct source of macroeconomic instability. This suggests that illiquidity shocks, measured by the stock price impacts, may contain more information than other types of shocks in recent studies, such as financial shocks and uncertainty shocks.
\end{abstract}

Keywords: Stock Market Illiquidity, Vector Autoregression, Great Recession JEL Classification: C32, E32.

\footnotetext{
*Department of Finance, University of Mannheim. Mannheim, Germany. E-mail: yen.chiayi@gmail.com

${ }^{\dagger}$ Corresponding author. Department of Civic Education and Leadership, National Taiwan Normal University. No.162, Section 1, Heping East Road, Da-An District, Taipei, Taiwan, 106. E-mail: yhchou@ntnu.edu.tw, Tel: (+886)-2-7734-1857, Fax: (+886)-2-2363-8821.

${ }^{\ddagger}$ We would like to thank Qinglai Meng (Co-Editor), three anonymous reviewers, Seohyun Lee, Chiahui Lu, Kuan-jen Chen, and the participants at WEAI 15th International Conference, the Conference of Methods and Applications on Economic Forecasts and the 2019 Taiwan Economics Research in Academia Sinica, and the participants at the joint internal seminar of Prof. Ruenzi and Prof. Niessen-Ruenzi at University of Mannheim for helpful comments and suggestions. This Research was supported by a Grant from the Ministry of Science and Technology, R.O.C. (MOST-105-2410-H-003-147-).
} 


\section{Introduction}

Declines in liquidity in equity markets became an important issue following the 20082009 financial crisis, as well as other recession periods dating back to the 1950s (Chen et al., 2016, 2018; Næs et al., 2011). There are a number of ways that stock market liquidity can affect the real economy. For example, Levine and Zervos (1998) find that the investment channel within a liquid secondary market can facilitate the financing of long-run productivity growth, thereby promoting economic growth. In addition, Longstaff (2004) proposes the "flight-to-liquidity" hypothesis, which points out that stock market liquidity may uncover information for investors. For example, when a negative event hits the economy, a future recession may be anticipated, in which case investors are likely to rebalance their portfolios toward safer assets, such as government bonds, and away from riskier assets such as stocks; thus, stock market liquidity shrinks. Brunnermeier and Pedersen (2009) construct a theoretical model that links assets' market liquidity and investors' funding liquidity. During a financial crisis, a shock to funding liquidity results in higher margins and worsens investors' funding conditions, which forces institutional investors to deleverage and provide liquidity to low margin stocks, leading to procyclical market liquidity provision.

Meanwhile, a number of empirical studies document that stock market liquidity and the state of the economy are indeed connected. For instance, by examining the forecasting performance of real economic activity, Næs et al. (2011) and Chen et al. (2018) show that Amihud (2002)'s stock market illiquidity ratio outperforms other conventional business cycle predictors, such as term spreads and credit spreads. Florackis et al. (2014) find a statistically significant negative relationship between stock market illiquidity and future UK gross domestic product (GDP) growth. Furthermore, Chen et al. (2016) also demonstrate that the stock market illiquidity ratio is a strong predictor of future recessions. Ellington et al. (2017) use a Bayesian time-varying parameter vector autoregression (TVP-VAR) with stochastic volatility to investigate illiquidity shocks to the stock market and housing market on real GDP in the US. They find that illiquidity shocks explain a large portion of real GDP growth, particularly during crisis periods. Building on a similar TVP-VAR framework, Ellington (2018) studies the impacts of shocks from stock market illiquidity using UK data, and finds that the effects of illiquidity shocks are substantial as well. 
While these studies focus on gauging the effect of illiquidity shocks on real GDP growth across different illiquidity measures, they have overlooked possible impacts of illiquidity shocks on other important macroeconomic variables related to the business cycle, such as consumption, unemployment rate, wages, and labor hours.

In this paper, we use a linear vector autoregression (VAR) model to analyze the role of stock market illiquidity shocks in explaining a wide range of macroeconomic and financial variables, including a set of variables related to the real economy, labor markets, and financial markets in the US from 1973M1 to 2018M12. We add labor market variables into our VAR model because stock market illiquidity is often considered a financial friction, which amplifies cyclical fluctuations in labor markets, as indicated in Petrosky-Nadeau and Wasmer (2013, 2015). Furthermore, we add consumption into our VAR model, and this is motivated by recent asset pricing studies focusing on consumption growth and disappointment-aversion. Delikouras and Kostakis (2019) point out that a fall in consumption can be a leading indicator of recession, and we argue that illiquidity, known as a strong predictor of recession, can be associated with consumption.

To measure stock market illiquidity, we adopt the illiquidity ratio proposed by Amihud (2002) for two reasons. First, a high degree of stock market liquidity means an asset can be sold in a short period of time with minimal price impact when a transaction occurs. Thus, the measures of stock market liquidity in the literature are in general related to transaction costs, trading volumes, and the ability to capture price impacts. Goyenko and Trzcinka (2009) and Goyenko and Ukhov (2009) find that Amihud (2002)'s illiquidity measure does a better job at capturing price impacts compared with several liquidity measures proposed in the existing literature, including those proposed by Lesmond et al. (1999), Roll (1984). Second, as indicated by Ellington (2018), the concept of price impact is consistent with studies that use dynamic stochastic general equilibrium models featuring asymmetric information to motivate liquidity constraints and show how financial frictions can propagate shocks to economic activity (Bigio and Schneider, 2017; Kiyotaki and Moore, 2005, 2019). For instance, Kiyotaki and Moore (2019) assume that, because of limited commitment, there exists constraints on resaleability of private claims involving borrowers reselling an exogenous fraction of their land and capital holdings in order to finance an investment opportunity. As the price impact rises, the ease of reselling assets 
declines, and this in turn increases transaction costs and deteriorates the attractiveness of investment, which ultimately causes the output to fall.

We identify illiquidity shocks in a VAR model using the maximum forecast error variance (MFEV) identification approach proposed by Uhlig $(2003,2004) .{ }^{1}$ This approach has two desirable features. First, the MFEV approach can be implemented either using a VAR in levels that includes nonstationary variables, or with a stationary VAR. It does not rely on precise specifications about the common stochastic trend in the variables of interest (Francis et al., 2014). Second, the approach can be applied to VARs with many endogenous variables without imposing additional restrictions on other shocks, which usually would create debate or potentially invalidate the model.

Our empirical analysis shows that the shocks that increase stock market illiquidity, namely illiquidity shocks, lead to significant declines in industrial production, consumption, and employment. Monetary policy is eased significantly in response to the increased illiquidity. Despite the decline in long-term Treasury yields, this shock causes a sharp fall in stock prices.

Furthermore, to gauge the historical contribution of illiquidity shocks, we adopt a two-step estimation strategy proposed by Kilian (2009), which maps illiquidity shocks at a monthly frequency to quarterly fluctuations in consumption, investment, real GDP, and unemployment rate. We find that illiquidity shocks explain the decline in economic activity during recession periods exceptionally well. For instance, the cumulative effect of illiquidity shocks explains the fall in consumption, investment, and real GDP at the height of the 2008-2009 financial crisis period. It also explains the high and persistent unemployment rate in the subsequent "jobless recovery" period.

Figure 1 serves to illustrate the historical effects of illiquidity shocks on annualized quarterly changes in consumption, investment, unemployment rate, and real GDP. Clearly, the cumulative effect of illiquidity shocks captures the important swings in the cyclical patterns of these macroeconomic variables, particularly during recession periods. Figure 2 depicts the portion of the forecast error variance for log of manufacturing industrial production, log of private employment, log of real personal consumption expenditures

\footnotetext{
${ }^{1}$ See Barsky and Sims (2011), Kurmann and Otrok (2013), and Ben Zeev and Khan (2015) for empirical applications of this method.
} 
(PCE), log of PCE deflators, 10-year Treasury yield, and log of real S\&P 500 stock price index that is attributable to the illiquidity shocks identified from our benchmark VAR model. The solid lines show the amount of variation in the forecast error variance of these variables that are attributable to illiquidity shocks, and the dashed lines are the associated $90 \%$ bootstrapping confidence intervals. We find that illiquidity shocks account for a maximum of nearly $20 \%$ of the variation in industrial production, $30 \%$ of the variation in employment, $10 \%$ of the variation in real PCE and PCE deflator, $12 \%$ of the variation in 10-year Treasury yield, and $10 \%$ of the variation in stock prices, respectively. This demonstrates that illiquidity shocks explain the majority of business cycle fluctuations and play a nontrivial role in explaining long-term government bond yields and stock price fluctuations.

Our empirical results show that illiquidity shocks have important macroeconomic implications for the US economy, and they provide information beyond other types of shocks related to the financial market disruptions discussed in the literature, such as financial shocks and uncertainty shocks (Bloom, 2009; Born et al., 2018; Caldara et al., 2016; Gilchrist and Zakrajsek, 2012; Jurado et al., 2015, and the references therein). In addition, our identified illiquidity shocks represent a distinct source of macroeconomic instability, and their effects differ from those of other macroeconomic shocks in the literature. Furthermore, we show that the cumulative effect of illiquidity shocks was an essential contributor to the depth and duration of the associated economic downturn known as the Great Recession, and that it also outperforms the role of uncertainty shocks documented by Born et al. (2018).

This paper is organized as follows. Sections 2 and 3 present the theoretical motivation and the empirical framework, respectively. Section 4 describes the proxy of stock market liquidity, data, and VAR specification. Section 5 outlines the benchmark empirical results. Section 6 provides the robustness checks. Section 7 compares illiquidity shocks with other types of shocks examined in the literature. Section 8 concludes. 


\section{Theoretical Motivation}

As we propose to use Amihud (2002)'s illiquidity ratio to identify illiquidity shocks, the question arises as to what mechanism lies behind the relation between illiquidity shocks and the macroeconomy. As shown in Ellington et al. (2017), Amihud (2002)'s illiquidity ratio is consistent with the theoretical model in Kiyotaki and Moore (2019). In the model of Kiyotaki and Moore (2019), because of borrowing constraints, the entrepreneurs who have investing opportunities can sell their holdings of liquid assets to finance their investments. However, they also face resaleability constraints. These two financial frictions are consequently related to liquidity. The definition of Amihud (2002)'s illiquidity ratio assumes that changes to asset prices depend on the net order flow. When prices become more sensitive to order flow, the ease of reselling assets declines, and this in turn causes investment to decline and, ultimately, output falls.

Before proceeding to our empirical analyses, we briefly describe the structure and implications of the theoretical model in Kiyotaki and Moore (2019) to motivate our empirical analysis. We will sketch the model here, and the details and quantitative analysis (including impulse response functions and variance decomposition) can be found in an online supplementary appendix.

The basic model of Kiyotaki and Moore (2019) is an infinite-horizon, discrete-time economy with five types of goods or assets: a nondurable output, physical capital, labor, equity, and fiat money. There are two types of agents: entrepreneurs and workers. All entrepreneurs have access to a technology for producing output goods. But in each period, only a fraction of entrepreneurs has investing opportunities to produce new capital from output goods. Investing entrepreneurs can acquire output goods for investment by issuing equity claims to future returns from the newly-produced capital, or selling the equity holdings of other agents that they acquired in the past.

Entrepreneurs with investing opportunities face two liquidity constraints on issuing and reselling equities. The first liquidity constraint is the borrowing constraint. This results from entrepreneurs who produce new capital but cannot precommit to working through their lifetime; thus, an investing entrepreneur who issues new equity can only pledge at most $\theta$ percent of future returns from his/her new capital. The second liquidity constraint is the resaleability constraint. As equity is less liquid than money, an agent 
can resell at most $\phi_{t}$ percent of his equity holdings. In Kiyotaki and Moore (2019), $\phi_{t}$ is assumed to be stochastic, and called a "liquidity shock".

In the online supplementary appendix, we calculate the impulse response functions of an "illiquidity shock" (i.e., $\phi_{t}$ falls). The impulse response function analyses indicate that, when the resaleability of equity falls and only slowly recovers, the investing entrepreneurs are less able to raise funds by selling their equity holdings. Therefore, investment decelerates and capital accumulation drops substantially, together with a fall in labor demand and wages. Consequently, output gradually decreases with persistently lower investment. As for consumption, it increases initially because of the substitution effect created by the increased funding difficulties. However, as output falls, the negative income effect decreases consumption. ${ }^{2}$

In sum, an illiquidity shock in Kiyotaki and Moore (2019) generates negative impacts on variables related to real macroeconomic activity, such as output, consumption, and employment, as well as the variables related to the nominal side of economy, such as the consumption good price and stock prices. We then conduct an empirical analysis to assess the theoretical implications of illiquidity shocks.

\section{$3 \quad$ Empirical Methodology}

In this paper, we extract the exogenous shocks that explain most of the forecast error variance of a target variable in a VAR, which in our case is the stock market illiquidity ratio. This identification strategy is based on the MFEV approach by Uhlig $(2003,2004)$. As noted earlier, the MFEV approach is a partial identification strategy that only identifies illiquidity shocks. Therefore, it can be implemented for a VAR without having to impose additional assumptions on other structural shocks (Barsky and Sims, 2011). The MFEV

\footnotetext{
${ }^{2}$ It is worth noting that equity prices tend to increase when facing a negative liquidity shock in the basic model Kiyotaki and Moore (2019). Kiyotaki and Moore (2019) show that this can be justified because the gap between Tobin's $q$ and unity, as a measure of the tightness of the liquidity constraint, increases because of the fall in $\phi_{t}$. Kiyotaki and Moore (2019) show that this shortcoming can be remedied by augmenting the model to include "storage", which is an alternative means of short-term saving besides money and provides an alternative liquid investment technology available to agents in the model. Kiyotaki and Moore (2019) show that in their full model with storage and government, when a negative liquidity shock hits the economy, the flight-to-liquidity effect is more pronounced and equity prices fall as a result.
} 
approach can be implemented as follows. First, consider a reduced form $\operatorname{VAR}(p)$ as follows:

$$
Y_{t}=\alpha+A_{1} Y_{t-1}+A_{2} Y_{t-2}+\cdots+A_{p} Y_{t-p}+u_{t}
$$

where $\alpha$ denotes the constant term, $Y_{t}$ is an $n \times 1$ vector of variables observed at time $t$, and $u_{t}$ is an $n \times 1$ vector of disturbances with variance-covariance matrix $\mathrm{E}\left(u_{t} u_{t}^{\prime}\right)=\Sigma$. The corresponding Wold vector moving average representation of (1) is:

$$
Y_{t}=\beta+B(L) u_{t},
$$

where $\beta$ denotes a constant, $B(L) \equiv I+B_{1} L+B_{2} L^{2}+\cdots$ is a $n \times n$ matrix polynomial in the lag operator $L$ of moving average coefficients.

To identify the structural shocks, we need to map the reduced form VAR disturbances $u_{t}$ to a vector of mutually orthogonal shocks $\epsilon_{t}$, i.e., $u_{t}=C \epsilon_{t}$. The conventional identification method of VARs requires us to impose restrictions on $C$, and $C$ must satisfy $\Sigma=\mathrm{E}\left(C \epsilon_{t} \epsilon_{t}^{\prime} C^{\prime}\right)=C C^{\prime}$, which implies $\mathrm{E}\left(\epsilon_{t} \epsilon_{t}^{\prime}\right)=I$. However, Uhlig (2003) argues that this method is not sufficient to identify $C$ because for any matrix $C$, there exists some alternative matrix $\tilde{C}$ such that $\tilde{C} Q=C$, where $Q$ is an orthonormal matrix, which satisfies $\Sigma=\tilde{C} \tilde{C}^{\prime}$. This alternative matrix $\tilde{C}$ maps $u_{t}$ into another vector of mutually orthogonal shocks $\tilde{\epsilon}_{t}$, i.e., $u_{t}=\tilde{C} \tilde{\epsilon}_{t}$. The identification problem becomes choosing an orthonormal matrix $Q$ that satisfies $\Sigma=\tilde{C} \tilde{C}^{\prime}$ for some arbitrary matrix $\tilde{C}$ (e.g., the Cholesky decomposition of $\Sigma)$.

Uhlig (2003)'s method consists of finding the $m<n$ columns of $Q$ defining the $m$ mutually orthogonal shocks that explain most of the variance of the forecast error of some variable in $Y_{t}$ over forecast horizon $\underline{k}$ to $\bar{k}$. Specifically, it denotes the $k$-step ahead forecast error of the $i$-th variable $y_{i, t}$ in $Y_{t}$ by:

$$
y_{i, t+k}-\mathrm{E}_{t} y_{i, t+k}=e_{i}^{\prime}\left[\sum_{l=0}^{k-1} B_{l} \tilde{C} Q \epsilon_{t+k-l}\right],
$$

where $e_{i}$ is a column vector with one in the $i$ th position and zeros elsewhere. Uhlig (2003)'s approach solves the problem as follows:

$$
Q_{m}^{*}=\arg \max _{Q_{m}} e_{i}^{\prime}\left[\sum_{k=\underline{k}}^{\bar{k}} \sum_{l=0}^{k-1} B_{l} \tilde{C} Q_{m} Q_{m}^{\prime} \tilde{C}^{\prime} B_{l}^{\prime}\right] e_{i}
$$


subject to $Q_{m}^{\prime} Q_{m}=I$, where $Q_{m}$ contains the columns of $Q$ defining the $m$ most important shocks. To solve this problem, consider first finding the shock, i.e., the column $q_{1}$ of $Q$ that explains most of the variance of the forecast error of variable $y_{i t}$ :

$$
q_{1}^{*}=\arg \max _{q_{1}} e_{i}^{\prime}\left[\sum_{k=\underline{k}}^{\bar{k}} \sum_{l=0}^{k-1} B_{l} \tilde{C} q_{1} q_{1}^{\prime} \tilde{C}^{\prime} B_{l}^{\prime}\right] e_{i},
$$

subject to $q_{1}^{\prime} q_{1}=1$. It is worth noting that the objective to be maximized can be expressed as:

$$
\begin{gathered}
e_{i}^{\prime}\left[\sum_{k=\underline{k}}^{\bar{k}} \sum_{l=0}^{k-1} B_{l} \tilde{C} q_{1} q_{1}^{\prime} \tilde{C}^{\prime} B_{l}^{\prime}\right] e_{i}=\sum_{k=\underline{k}}^{\bar{k}} \sum_{l=0}^{k} \operatorname{trace}\left[\left(e_{i} e_{i}^{\prime}\right)\left(B_{l} \tilde{C} q_{1}\right)\left(q_{1}^{\prime} \tilde{C}^{\prime} B_{l}^{\prime}\right)\right] \\
=\sum_{k=\underline{k}}^{\bar{k}} \sum_{l=0}^{k} \operatorname{trace}\left[\left(q_{1}^{\prime} \tilde{C}^{\prime} B_{l}^{\prime}\right)\left(e_{i} e_{i}^{\prime}\right)\left(B_{l} \tilde{C} q_{1}\right)\right] \\
=q_{1}^{\prime}\left[\sum_{k=\underline{k}}^{\bar{k}} \sum_{l=0}^{k} \tilde{C}^{\prime} B_{l}^{\prime}\left(e_{i} e_{i}^{\prime}\right) B_{l} \tilde{C}\right] q_{1} \\
=q_{1}^{\prime} S q_{1},
\end{gathered}
$$

with $S \equiv \sum_{k=k}^{\bar{k}} \sum_{l=0}^{k} \tilde{C}^{\prime} B_{l}^{\prime}\left(e_{i} e_{i}^{\prime}\right) B_{l} \tilde{C}$. Note that we order the $q_{1}$ vector first in $Q$. With this formulation, the maximization problem in (4) can be expressed as a Lagrangian problem as follows:

$$
\max _{q_{1}} \mathcal{L}=q_{1}^{\prime} S q_{1}-\lambda\left(q_{1}^{\prime} q_{1}-1\right)
$$

with first-order condition

$$
S q_{1}=\lambda q_{1}
$$

Note that (6) defines an eigenvalue decomposition, with $q_{1}$ being the eigenvector of $S$ that corresponds to eigenvalue $\lambda$. Furthermore, because $q_{1}^{\prime} q_{1}=1$, the first-order condition of (6) implies the eigenvalue $\lambda$ is the objective to be maximized, and $q_{1}$ that maximizes the variance is the normalized eigenvector associated with the largest eigenvalue $\lambda$. Similarly, $q_{2}$ is the second principal component and so forth for all the $m$ components of $Q_{m}^{*}$ that we want to extract. Once $Q_{m}^{*}$ is identified, we can study the impulse response functions in $Y_{t}$ with respect to each column of $Q_{m}^{*}$, and provide the economic interpretation. We focus on studying the shock that explains most of the forecast error variance in the target variable, which in our case is the stock market illiquidity ratio. 


\section{Construction of Illiquidity Measure, VAR Specifi- cation, and Data}

\subsection{Construction of $I L R_{t}$}

In this paper, we adopt Amihud (2002)'s illiquidity ratio to measure stock market illiquidity. Amihud (2002) measures stock market liquidity using a price impact measure using daily trading data as follows:

$$
I L R_{i, t}=\frac{1}{D_{i, t}} \sum_{d=1}^{D_{i, t}} \frac{\left|R_{i, t, d}\right|}{V O L_{i, t, d}},
$$

where $D_{i, t}$ is the number of available trading days for stock $i$ during period $t$. During period $t,\left|R_{i, t, d}\right|$ and $V O L_{i, t, d}$ are absolute returns and trading volume (in dollars) of stock $i$ during day $d$. That is, $I L R_{i, t}$ is calculated from the average ratio of absolute price changes to trading volumes, which captures the daily price impact of the order flow. Note that Amihud (2002)'s measure is called an illiquidity measure, as a high value of the measure indicates low liquidity (high price impact of transactions). That is, $I L R_{i, t}$ captures how much the price moves for each volume unit of trades. After constructing $I L R_{i, t}$, the second step is to calculate aggregated $I L R_{t}$ as a measure of average market illiquidity across stocks in a particular period $t$ (for instance, month $t$ ):

$$
I L R_{t}=\frac{1}{N_{t}} \sum_{i=1}^{N_{t}} I L R_{i, t}
$$

where $N_{t}$ is the number of stocks in period $t$. We then use the averaged stock market illiquidity measure $I L R_{t}$ to conduct the empirical analysis. We follow Næs et al. (2011) and Chen et al. (2016) in scaling up $I L R_{t}$ by multiplying by $10^{6}$ because the original magnitude of the $I L R_{t}$ measure is too small to conduct a sensible empirical analysis.

Monthly data from 1973M1 to 2018M12 are used to construct Amihud (2002)'s illiq-

uidity measure. The monthly aggregated illiquidity measure is constructed using data of individual common stocks (codes 10 and 11) listed on the New York Stock Exchange (NYSE). All the stocks have to meet the following requirements.

1. The stock must have been traded for more than 200 days in the last year to ensure more stable estimates. 
2. The stock price must be greater than $\$ 5$ in the last trading day of the last year. This enables us to exclude noise from the estimates because a low-price stock can be affected easily by the minimum tick.

3. The stock must have market capitalization data in the Center for Research in Security Prices (CRSP) database at the end of last year. As a result, some derivative securities were excluded.

4. Any stock that satisfies the above conditions is excluded if it is an outlier, i.e., in the lowest $(1 \%)$ or highest $(99 \%)$ tails of the distribution of $I L R_{i, t}$.

All the daily stock market data are obtained from the CRSP database, including prices and trading volumes. A description of $I L R_{t}$ is listed in the first column of Table $1 .{ }^{3}$ In the first panel of Figure $3, I L R_{t}$ is plotted, with shaded areas indicating the NBER recession periods. Clearly, the $I L R_{t}$ is closely related to business booms and recessions: a rapid increase in the illiquidity measure is generally accompanied by a recession. Similar findings are obtained for the annual growth rate of $I L R_{t}$, which is plotted in Figure 4.

\subsection{VAR Specification and Data}

Our benchmark specification of the VAR includes nine variables: (1) Amihud (2002)'s stock market illiquidity measure; (2) log of manufacturing industrial production index; (3) log of private employment; (4) log of real PCE; (5) log of PCE price deflator; (6) Federal funds rate; (7) nominal 10-year Treasury yield; (8) log of real S\&P 500 Composite Stock Price Index; and (9) log of S\&P Goldman Sachs Commodity Index (GSCI). Data for (2) to (7) are collected from the Federal Reserve Economic Data (FRED) database provided by the Federal Reserve Bank of St. Louis, (8) is obtained from Robert Shiller's website, and (9) is from Datastream. The sample period is 1973M1 to 2018M12, and we estimate the VAR using ordinary least squares and include a constant term. We estimate the VAR in levels of all variables, because this will produce consistent estimates of the impulse response functions, and is robust for cointegrating relationships among the endogenous

\footnotetext{
${ }^{3}$ Over the sample period, the number of stocks included in the illiquidity proxy each month ranges from 1002 to 1654, while the average number of stocks included is 1228 .
} 
variables (Ben Zeev and Khan, 2015; Kurmann and Otrok, 2013). Finally, the lag length of the VAR is chosen to be four, which is suggested by the Akaike information criterion. ${ }^{4}$

In Section 5.2, we investigate the historical significance of illiquidity shocks obtained from the benchmark VAR on the quarterly change in consumption $C O N S_{t}$, investment $I N V_{t}$, unemployment rate $U E M P_{t}$, and real output $R G D P_{t}$. We proxy $C O N S_{t}, I N V_{t}$, $U E M P_{t}$, and $R G D P_{t}$ by real PCE, gross private domestic investment, unemployment rate of full-time workers, and real gross domestic product, respectively. All series are seasonally adjusted. $R G D P_{t}$ and $I N V_{t}$ are from the FRED database, $U E M P_{t}$ is from the US Bureau of Labor Statistics, and CONS $S_{t}$ is from the US Department of Commerce.

\section{$5 \quad$ Empirical Results}

\subsection{Impulse Response Analysis and Forecast Error Variance De- composition}

As described in Section 3, we extract the shocks that maximize the forecast error variance of stock market illiquidity measures over a specific forecast horizon. We set the forecast horizon to $0<k<180$ months; this choice enables us to capture short-run movements in stock market illiquidity, while also providing reliable estimates at the long end of the forecasting horizon. ${ }^{5}$ We limit our analysis to one shock because we find that one shock explains virtually all the movement in stock market illiquidity.

Figure 5 displays the impulse response functions of the endogenous variables to a one standard deviation shock to illiquidity, together with $90 \%$ bootstrapped confidence intervals, which are constructed based on 5000 bootstrap replications. ${ }^{6}$ A one standard deviation shock to illiquidity causes stock market illiquidity to increase by about 12 basis points, leading to a hump-shaped and significant reduction in real economic activity, with industrial production, employment, and consumption all falling in subsequent months. For instance, the level of industrial production has decreased by about 60 basis points 10

\footnotetext{
${ }^{4}$ We set the maximum lag length of the VAR equal to eight in order to choose the optimal lag length.

${ }^{5}$ The results are unchanged when using alternative settings. For brevity, these results are not reported but are available upon request.

${ }^{6}$ The bootstrapped confidence intervals are constructed using Hall (1992)'s bootstrapping methodology.
} 
months after the shock, while the drop in employment and consumption seems to be less severe but persistent. This demonstrates that an illiquidity shock has negative impacts on the real economy. However, while an illiquidity shock in Kiyotaki and Moore (2019) acts as an adverse demand shock, we find an increase in the price variables, such as PCE deflator, Federal funds rate, and GSCI. For instance, the PCE deflator tends to increase (but is statistically insignificant) initially and falls after 10 months, and Federal funds rate also rises in respond to an illiquidity shock initially. These results can be explained by the fact that the responses of real macroeconomic aggregates (output, employment, and consumption) to an illiquidity shock exhibit an inverted hump-shaped pattern. This implies that the subsequent recession will occur three to 10 months after an illiquidity shock hits the economy. Thus, the resulting economic contraction leads to a fall in the price level after 10 months. Furthermore, four months after the initial impacts of the illiquidity shock, monetary policy is eased significantly (Federal funds rate falls) in response to the adverse economic conditions. Meanwhile, the reduction in the Federal funds rate is accompanied by a decline in longer-term Treasury yields. The effects of an illiquidity shock on the stock market is substantial; the stock market index experiences a sharp drop of around 136 basis points. Finally, GSCI increases in response to the illiquidity shock. This can be attributed to the demand for a portfolio hedge by stock market participants, because they may want to invest in commodities to buffer a decline in stock prices.

Table 2 reports the fraction of the forecast error variance in industrial production, employment, real PCE, and stock market index explained by illiquidity shocks.

Illiquidity shocks account for nearly $20 \%$ of the variation in industrial production and employment, and $10 \%$ of the variation in real PCE beyond the one-year forecasting horizon. The lower panel of Table 2 reports the forecast error variance decomposition results using $p=2$ as the lag length in the VAR, which is suggested by the Schwarz Information Criterion. Clearly, the results are quantitatively similar. The macroeconomic dynamics reported above thus suggest that illiquidity shocks have important implications for real economic activity. In addition, our results also suggest that a negative liquidity shock can cause investment to decline because the resaleability constraint of assets is tightening, which induces a prolonged contraction in economic activity, i.e., output and consumption fall (Bigio and Schneider, 2017; Kiyotaki and Moore, 2019; Shi, 2015) 


\subsection{Cumulative Effects of Illiquidity Shocks on Quarterly Macroe- conomic Aggregates}

In this section, we follow Born et al. (2018) by employing the two-step procedure proposed by Kilian (2009) to investigate the effect of illiquidity shocks on macroeconomic variables at a quarterly frequency. The reason for using the two-step method is twofold. First, the identifying assumptions imposed on the structural VAR could be arguably too strong when constructing a VAR using quarterly data. ${ }^{7}$ Second, if researchers attempt to avoid this problem and use monthly data, it is common to use manufacturing industrial production, or a monthly interpolated GDP time series as a proxy for GDP at a monthly frequency. However, manufacturing industrial production only accounts for about $12 \%$ of GDP in the US, and the interpolated GDP series might create spurious dynamics.

The two-step method can be implemented as follows. First, we follow Kilian (2009) to construct measures of quarterly liquidity shocks by averaging monthly illiquidity shocks obtained from our benchmark VAR for each quarter.

$$
\hat{\zeta}_{I L R, t}=\frac{1}{3} \sum_{i=1}^{3} \hat{\epsilon}_{I L R, i, t},
$$

where $\hat{\epsilon}_{I L R, i, t}$ refers to the estimated residual for illiquidity shock in the $i$-th month of the $t$-th quarter of the sample. In the second step, we use the identified quarterly averaged monthly illiquidity shock $\hat{\zeta}_{I L R, t}$ to examine the cumulative effects of illiquidity shocks on the quarterly growth rates of consumption, investment, unemployment rate, and real GDP by estimating the following regression:

$$
Z_{t}=c+\sum_{i=0}^{12} \phi_{i} \hat{\zeta}_{I L R, t-i}+\epsilon_{t},
$$

\footnotetext{
${ }^{7}$ Imposing identification assumptions on quarterly data implies that all the interactions among endogenous variables occurs on a quarterly basis. For example, when applying the "recursive ordering" method to identify shocks, researchers usually impose zero restrictions on a matrix $C$ with a specific order of arrival times of shocks. For example, if an endogenous variable $y_{2}$ is ordered after another endogenous variable $y_{1}$, this implies the exogenous shock to $y_{2}$ can only affect $y_{1}$ with a period lag. If we use quarterly data, this means it takes three months for the shock to $y_{1}$ to affect $y_{2}$. This can arguably be too strong an assumption if $y_{2}$ is a "fast-moving" variable (e.g., stock market illiquidity) which contains future information on the macroeconomy. Moreover, although the MFEV approach we used is a partial identifying strategy and less restrictive, it could be sensitive to the truncation horizon $k$ when applied to quarterly data, because the interval $[\underline{k}, \bar{k}]$ is relatively small. See Beaudry et al. (2011) for a discussion.
} 
where $c$ denotes a constant, and $Z_{t}=\left(X_{t}-X_{t-4}\right) / X_{t-4}$ denotes the annualized growth rate of a quarterly measure of real economic activity $X_{t}$. Specifically, $X_{t}=C O N S_{t}$, $I N V_{t}, U E M P_{t}$, and $R G D P_{t}$. The number of lags is set to 12 quarters. The predicted

historical values $\hat{Z}_{t} \equiv \hat{c}+\sum_{i=0}^{12} \hat{\phi}_{i} \hat{\zeta}_{I L R, t-i}$ enable us to study the portion of the change in real economic activity that is attributable to illiquidity shocks over the sample period, i.e., we estimate the historical decomposition of the macroeconomic series at the quarterly level.

The results of this empirical exercise are presented in Figure 1. Overall, the cumulative effects of illiquidity shocks affect the cyclical behavior of real economic activity markedly, particularly during the recession periods. However, the timing and significance of illiquidity shocks vary considerably over different recession periods. For instance, the cumulative effect of illiquidity shocks appears to be an important contributor to the recessions of the early 1980s because it captures the immediate and substantial reductions in the growth rates of consumption, investment, and real GDP, and the sharp rise in the unemployment rate. As for the Great Recession in 2008-2009, the cumulative illiquidity shocks took effect in the second half of 2008, and their effect is persistent on real economic activity. Moreover, we found that illiquidity shocks explain variations in the unemployment rate exceptionally well during the recession periods, compared with the other macroeconomic aggregates. This is consistent with Figure 3 which shows that stock market illiquidity is typically high during recessions when the unemployment rate also tends to increase substantially.

In sum, according to our historical decomposition analysis, we found that illiquidity shocks explain quarterly economic activity in recession periods well in terms of magnitude and direction. This confirms the view of Chen et al. (2016) that the dynamic link between recessions and stock market liquidity is strong, and it also echoes the findings in Ellington et al. (2017) and Ellington (2018) that the magnitude of the effect of illiquidity shocks on real GDP is likely to be greater in recession periods.

\subsection{Firm Size Effect of Illiquidity Shocks}

Figure 1 shows that illiquidity shocks explain the swings in economic activity better in recessions than in normal times. As shown in Næs et al. (2011) and Chen et al. (2016), 
because small firms are relatively more sensitive to economic downturns than large firms, it is more likely that investors move away from stocks with lower liquidity when the economy is in recession, and the size of the liquidity shock to small firms should decline substantially to reflect this "flight to liquidity" effect. Thus, it is of interest to examine stock market illiquidity shocks arising from different firm size quartiles and compare the differences between the shocks arising from large firms and small firms in terms of size and quantitative importance.

By doing so, we construct the illiquidity measures for large and small firms, denoted as $I L R_{t}^{\text {Large }}$ and $I L R_{t}^{\text {Small }}$, respectively. Firms within the highest 25th percentile of market capitalization in the previous year are categorized as large, while those within the lowest 25th percentile in the previous year are denoted as small. The second and third columns of Table 1 list the descriptive statistics of large firms and small firms, respectively. ${ }^{8}$ It is clear that the mean of $I L R_{t}^{\text {Large }}$ is smaller than $I L R_{t}^{\text {Small }}$ as the large-capitalization firms are less illiquid. Moreover, the variations in $I L R_{t}^{\text {Small }}$ are greater than $I L R_{t}^{\text {Large }}$ and $I L R_{t}$. In the second and third panels of Figures 3 and 4 , we plot the level and growth rate of illiquidity measures $\left(I L R_{t}^{\text {Large }}\right.$ and $\left.I L R_{t}^{\text {Small }}\right)$ together with the NBER recession periods.

Table 3 reports the variance decomposition results for illiquidity shocks to $I L R_{t}^{\text {Large }}$ and $I L R_{t}^{\text {Small }}$, respectively. The fraction of the variation in economic activity attributable to illiquidity shocks to small-capitalization firms is larger than that to large-capitalization firms. For example, shocks to $I L R_{t}^{\text {Small }}$ explain $9.341 \%$ of the forecast error variance in industrial production, $15.423 \%$ in employment, and 9.302\% in PCE at $k=6$. By contrast, the corresponding numbers for the shocks to $I L R_{t}^{\text {Large }}$ are $3.621 \%, 7.160 \%$, and $4.191 \%$, respectively, Thus, illiquidity shocks to $I L R_{t}^{\text {Small }}$ explain nearly double the variation in industrial production, employment, and PCE compared with the shocks to ILR $R_{t}^{\text {Large }}$.

Figure 6 plots the responses of the endogenous variables in our benchmark VAR to a one standard deviation illiquidity shock to each of $I L R_{t}^{\text {Large }}$ and $I L R_{t}^{\text {Small }}$, together with our benchmark illiquidity shock to $I L R_{t}$ and its corresponding $90 \%$ bootstrapping bands. The responses of industrial production, employment, and PCE to an illiquidity

\footnotetext{
${ }^{8}$ Over the sample period, the number of stocks included in the illiquidity proxy using only small (large) stocks each month ranges from 234 (252) to 398 (422), while the average number of stocks included is $293(314)$.
} 
shock to $I L R_{t}^{\text {Small }}$ are nearly as sharp and immediate as the benchmark illiquidity shock to $I L R_{t}$, and the magnitude of illiquidity shock to $I L R_{t}^{\text {Small }}$ is appreciably larger than that to $I L R_{t}^{\text {Large }}$. However, an illiquidity shock to both $I L R_{t}^{\text {Large }}$ and $I L R_{t}^{\text {Small }}$ lie within the $90 \%$ bootstrapping bands based on the illiquidity shock to $I L R_{t}$, which means our baseline results obtained from an illiquidity shock to $I L R_{t}$ are not implausible. Figure 7 displays the effects of illiquidity shocks to $I L R_{t}^{\text {Large }}$ and $I L R_{t}^{\text {Small }}$ over the sample periods, together with the quarterly annual growth rates of consumption, investment, unemployment rate, and real GDP. Although the comovement between illiquidity shocks to $I L R_{t}^{\text {Small }}$ and $I L R_{t}^{\text {Large }}$ is positive in general, the implied path based on the shock to $I L R_{t}^{\text {Small }}$ tracks the actual growth rates of $C O N_{t}, I N V_{t}, U E M P_{t}$, and $R G D P_{t}$ more closely during recession periods, especially in the Great Recession period.

To highlight this, Table 4 reports the effects on real economic activity of all illiquidity measures from 2008 to 2018 . To better identify the relative contribution of illiquidity shocks to economic fluctuations, we present the data at an annual frequency. We find that the variations in the annual growth rates of our economic activity measures attributable to illiquidity shocks to $I L R_{t}$ and $I L R_{t}^{\text {Small }}$ are very similar. Furthermore, illiquidity shocks to both $I L R_{t}$ and $I L R_{t}^{\text {Small }}$ had negative effects on real GDP growth rate in 2009, causing $2.098 \%$ and $1.963 \%$ reductions in real GDP growth, respectively. It is worth noting that illiquidity shocks to $I L R_{t}$ explain $1.516 \%$ of the reduction in real GDP from 2008 to 2009 (i.e., $0.582 \%$ - 2.098\%). As the actual real GDP growth rate fell by $2.887 \%$ and $5.280 \%$ in 2008 and 2009 respectively, illiquidity shocks to $I L R_{t}$ account for $18.563 \%$ of the variation in real GDP growth. This result is close to that reported in Ellington et al. (2017), where stock market illiquidity shocks explained $17 \%$ of the overall variation in GDP growth during the Great Recession. Similar results are found for illiquidity shocks to $I L R_{t}^{\text {Small }}$, and the overall contribution of illiquidity shocks to $I L R_{t}^{\text {Large }}$ on real GDP growth reductions is much smaller than $I L R_{t}$ and $I L R_{t}^{\text {Small }}$. Similarly, illiquidity shocks also explain negative growth in consumption and investment over the years 2008 and 2009, which suggests that illiquidity shocks are an important factor in explaining the reductions in measures of economic activity during the height of the Great Recession. In particular, illiquidity shocks play an important role in characterizing the unemployment rate dynamics. At a maximum (across all illiquidity measures), illiquidity 
shocks explained nearly $23.841 \%$ of the sharp increase in the unemployment rate in 2009 . From 2010 to 2014, illiquidity shocks still contributed nearly $-2.7 \%$ to the growth rate in unemployment on average, which is greater than the actual change in the unemployment rate. This suggests that illiquidity shocks are an essential factor in explaining the slow and moderately decreasing unemployment rate (i.e., the unemployment rate remained at a persistently high level) after the Great Recession. This result is, thus, consistent with the theoretical result of Bigio (2015) that the shortfall in liquidity from selling capital will increase the cost of obtaining liquidity to finance payroll employment. In addition, it also echoes the empirical findings in Chodorow-Reich (2014) that the disruption to credit markets accounts for a sizable share of the decline in the employment rate, particularly in small firms, in the year following the Lehman bankruptcy. Finally, our finding also suggests that illiquidity shocks outperform uncertainty shocks in explaining variation in the unemployment rate, as Born et al. (2018) finds that uncertainty shocks only play a minor role in explaining the "jobless recovery" phenomenon after the Great Recession.

Overall, our results support the hypothesis of "flight to liquidity", in that the illiquidity measure of small firms is more informative about economic activity than that of large firms, especially during recessions. This is also consistent with the empirical findings of Chen et al. (2016) and Næs et al. (2011) in the context of forecasting performance.

\section{Robustness Checks}

In this section, we set $p=4,0<k<180$ and implement a number of robustness checks, including different approaches to identifying illiquidity shocks, different sets of endogenous variables in the VAR, a different measure of stock market liquidity, an alternative monetary policy indicator, and different subsample periods. We also investigate the possible asymmetry of illiquidity shocks.

\subsection{Alternative VAR Identification Schemes}

We consider two alternative identification schemes for illiquidity shocks. Rather than using the MFEV method, we use the Cholesky decomposition method to obtain the lower triangular matrix $C$, which maps reduced-form VAR disturbances $u_{t}$ into $\epsilon_{t}$, but the 
ordering of the endogenous variables is different under these two identification schemes.

The first strategy is a recursive scheme with $I L R_{t}$ ordered first. This is motivated by the Granger causality test in Næs et al. (2011), where the null hypothesis that $I L R_{t}$ does not Granger cause the real GDP growth is strictly rejected, while the reverse hypothesis is not. This implies that $I L R_{t}$ is likely to be an exogenous source of economic fluctuations, rather than an endogenous response to other economic shocks. The second identification scheme follows Jurado et al. (2015) and Gilchrist and Zakrajsek (2012) in identifying uncertainty and financial shocks, respectively. We assume that $I L R_{t}$ is ordered after industrial production, employment, PCE, and PCE deflator, which implies that illiquidity shocks affect economic activity with a one-period lag, while GSCI index, S\&P 500 index, 10-year Treasury bond yield, and Federal funds rate are ordered after $I L R_{t}$, which means that financial and monetary market variables can react to illiquidity shocks contemporaneously.

Figures 8 and 9 depict the results of the impulse response functions using the identification schemes described above. Illiquidity shocks clearly have significant adverse impacts on real economic activity, and the sizes of the effects are similar to the benchmark result in Figure 5. For instance, a one-standard-deviation illiquidity shock leads to a fall in industrial production of a maximum of about 60 basis points for both identification schemes, which is close to the estimates reported in our benchmark VAR. Table 5 reports the corresponding forecast error variance decomposition results. It is evident that illiquidity shocks still appear to be an important driver of fluctuations in economic activity. Overall, our baseline results are not affected substantially by different identification assumptions about structural shocks. This also highlights the advantages of using a monthly VAR to identify illiquidity shocks because imposing different restrictions on $C$ does not alter the empirical results significantly (Born et al., 2018; Kilian, 2009).

\subsection{Alternative Specifications of VAR}

We also consider two alternative VAR specifications and examine the robustness of our baseline findings. The first VAR is an eight-variable VAR (denoted as VAR-8) and includes a stock market illiquidity measure, log of real S\&P 500 index, Federal funds rate, log of nominal wages, log of consumer price index (CPI), log of labor hours, log of employment, 
and log of manufacturing industrial production index as endogenous variables. Compared with our benchmark VAR specification, it contains more labor market variables, such as labor hours and log of nominal wages, and uses CPI as a measure of the price level rather than using the PCE deflator. The second VAR is a 12-variable quarterly VAR (denoted as VAR-12) which includes the variables used in our benchmark VAR (variables (1)-(9) in Section 4.2), together with three additional variables related to the supply side of the economy: log of total factor productivity (TFP), log of relative price of investment goods, and the log of oil price.

All data for VAR-8 and VAR-12 are obtained from the FRED database. We use the utilization-adjusted TFP series provided by Fernald (2014) and the quarterly average of West Texas Intermediate spot crude oil for the nominal oil price, deflated using the PCE deflator to obtain the real oil price. ${ }^{9}$ The relative price of investment goods is calculated as the investment deflator divided by the consumption deflator, as in DiCecio (2009).

We estimate the impulse responses from VAR-8 and VAR-12 using the MFEV approach, which maximizes the forecast error variance of the stock market illiquidity ratio. 10 Figure 10 depicts the dynamic responses of the endogenous variables in VAR-8. It is clear that shocks to $I L R_{t}$ sharply reduce the stock market index, employment, and industrial production. It appears to have larger and somewhat more persistent effects than our benchmark VAR. However, the responses of CPI and labor hours to an illiquidity shock appear to be insignificant past the 24-month horizon, while the response of wages to an illiquidity shock is only marginally different from zero for six to 14 months, becoming zero thereafter. For VAR-12, we report estimates of the impulse response functions for 20 quarters in Figure 11. We find a one-standard-deviation illiquidity shock has similar adverse macroeconomic impacts as in our benchmark VAR, which employs monthly data. The illiquidity shock also reduces TFP and real oil price; however, its impacts are statistically insignificant. Finally, we find that the relative price of investment goods increases significantly in response to an illiquidity shock after four quarters and beyond. This is similar to the empirical finding on uncertainty shocks documented by Katayama and Kim (2018) that increased uncertainty induces a rise in relative price of investment

\footnotetext{
${ }^{9}$ We follow Fernald (2014) to aggregate the quarterly growth rates to create a log-level TFP series.

${ }^{10}$ Because we use quarterly data in VAR-12, we set the lag length equal to two, and we set the forecast horizon equal to $0<k<40$.
} 
goods. Along with the historical decomposition shown in Figure 1 in Section 5.2, illiquidity shocks can depress investment spending. We, thus, conclude that illiquidity shocks could act as adverse supply shocks to investment because they generate the negative relationship between the relative price and quantity of investment. This is consistent with the theoretical interpretation of the "investment channel" which relates to the relationship between stock market illiquidity and real economic activity documented by Levine (1991). In Levine (1991), an illiquid stock market can increase the cost of human capital for firms, discourage the firm to invest, and subsequently reduce productivity. ${ }^{11}$ Overall, we conclude that the impacts of illiquidity shocks from VAR-8 and VAR-12 on economic activity, such as industrial production and employment, are qualitatively similar to those in our benchmark VAR.

\subsection{An Alternative Measure of Stock Market Liquidity}

We consider an alternative measure of stock market liquidity proposed by Pastor and Stambaugh (2003) as an additional robustness test of the main argument in this paper, i.e., stock market liquidity (or illiquidity) affects economic activity strongly.

The monthly measure of stock market liquidity proposed by Pastor and Stambaugh (2003) is an average of individual stock measures estimated with daily data, and this reflects the principle that order flow induces greater return reversals when stock liquidity is lower. To construct a stock market liquidity risk factor, we follow Pastor and Stambaugh (2003) to estimate the following regression with daily data for month $t$ and stock $i$ :

$$
r_{i, d+1, t}^{e}=\theta_{i, t}+\phi_{i, t} r_{i, d, t}+\gamma_{i, t} \operatorname{sign}\left(r_{i, d, t}^{e}\right) v_{i, d, t}+\epsilon_{i, d+1, t},
$$

where $r_{i, d, t}$ is the return on stock $i$ on day $d$ in month $t$. The excess return $r_{i, d, t}^{e}=$ $r_{i, d, t}-r_{m, d, t}$ of stock $i$ is measured as the difference between the return on stock $i\left(r_{i, d, t}\right)$ and the CRSP value-weighted market return on day $d$ in month $t\left(r_{m, d, t}\right)$. The $\operatorname{sign}\left(r_{i, d, t}^{e}\right)$

\footnotetext{
${ }^{11}$ This seems at odds with the interpretation of the impacts of illiquidity shocks on real economic activity in our benchmark empirical findings, which is more like a demand-side mechanism because positive co-movement in price and quantity of investment goods is expected. Further disentangling the demand-side and supply-side effects of illiquidity shocks on macroeconomic variables from a theoretical or empirical perspective is beyond the scope of the current study, and, therefore, we will leave this for future research.
} 
variable is equal to 1 when excess returns are positive and equal to -1 when excess returns are negative. We define $v_{i, d, t}$ as the dollar volume for stock $i$ on day $d$ in month $t$. The signing of the trading volume is meant to distinguish whether trades are driven by selling pressure from investors or by buying pressure. When investors are selling stocks to market makers or other short-term liquidity providers such as speculators, excess returns on those stocks should be negative. When investors are buying from market makers, excess returns should be positive. The intuition behind equation (10) is that the signed volume (order flows) causes price pressure on day $d$ that will partly revert on the next day. The reversion is stronger when stock $i$ is more illiquid. That is, one would expect $\gamma_{i, t}$ to be negative in general and larger in absolute magnitude when liquidity is lower.

Finally, the monthly market-wide measure of illiquidity is obtained by

$$
\hat{\gamma}_{t}=\frac{1}{N_{t}} \sum_{i=1}^{N} \hat{\gamma}_{i, t},
$$

where $N_{t}$ is the number of stocks in the sample in month $t$. Finally, we denote $L I Q_{t}=\hat{\gamma}_{t}$ as Pastor and Stambaugh (2003)'s liquidity factor.

We obtain the liquidity data from Lubos Pastor's website and use the data as an alternative measure of stock market liquidity to investigate the dynamic impacts of liquidity (or illiquidity) shocks on the macroeconomy. ${ }^{12}$ Figure 12 displays the impulse response functions of the endogenous variables to a shock to Pastor and Stambaugh (2003)'s measure of liquidity. It is worth noting that because Pastor and Stambaugh (2003)'s measure represents the degree of stock market liquidity rather than illiquidity, a one-standard-deviation liquidity shock causes $L I Q_{t}$ to rise. Furthermore, we find liquidity shocks implied by $L I Q_{t}$ have significant favorable effects on macroeconomic variables in general. However, compared with our benchmark VAR in Section 5.1, the impact of liquidity shocks on the macroeconomy is relatively small and short-lived. For instance, a one-standard-deviation liquidity shock causes industrial production to rise, but the magnitude of the maximum response is less than 40 basis points; the responses of employment and PCE also have similar patterns. Nevertheless, the liquidity shocks implied by $L I Q_{t}$ still have significant positive effects on macroeconomic variables in general.

\footnotetext{
${ }^{12}$ Lubos Pastor's website: http://faculty .chicagobooth.edu/lubos.pastor/research/
} 


\subsection{Problem of Monetary Policy at Zero Lower Bound}

The sample period in this paper covers the period after December 2008, during which the Federal Reserve lowered the Federal funds rate to the zero lower bound (ZLB), and kept it at historically low levels. The inability of monetary policy to accommodate the impacts of illiquidity shocks when the ZLB is binding implies that our VAR model could be misspecified. To examine the importance of this issue for our results, we consider two alternative VAR specifications. First, we replace the Federal funds rate with the shadow Federal funds rate constructed by Wu and Xia (2016) as an indicator of monetary policy, which is not bounded below by zero and is supposed to summarize the stance of monetary policy. ${ }^{13}$ Second, we estimate a VAR using a subsample from 1973M1 to 2008M9, which excludes the years affected by the ZLB. Figures 13 and 14 show the impulse responses to a one standard deviation illiquidity shock using these two VAR specifications. Clearly, the results are consistent with our benchmark findings in Figure 5, both in terms of magnitude and persistence, and we confirm again that illiquidity shocks have significant adverse effects on the macroeconomy.

\subsection{Subsample Analysis}

In Figure 3, several large positive spikes appear in the early 1970s, and illiquidity ratios exhibit an apparent downward trend over the whole sample period. Amihud (2019) indicates that the declining trend in illiquidity can be partly explained by institutional changes in the securities markets and by the means developed to circumvent the costs of illiquidity. For example, a strong downward trend in the illiquidity ratio is found in 1980s, because many discount brokers entered the market which increased competition in the brokerage industry and facilitated trading and lowered the cost of trading especially for small investors. This in turn improved stock market liquidity; thus, illiquidity fell dramatically. Moreover, it is widely accepted that, for a number of macroeconomic variables, there were breaks in volatility following the Great Inflation and again during the Great Recession. As our sample period (1973M1-2018M12) encompasses the Great Inflation and Great Recession periods, this may be problematic. Regarding these concerns, we conduct

\footnotetext{
${ }^{13}$ The shadow rate of the US from $1960 \mathrm{M} 1$ to $2015 \mathrm{M} 11$ can be downloaded at https://sites.google.com/view/jingcynthiawu/shadow-rates
} 
three subsample analyses covering 1976M1-2018M12, 1973M1-2007M12, and 1983M12007M12, respectively. The first subsample excludes the large swings in $I L R_{t}$ in the early 1970s, and the second subsample excludes the Great Recession period because illiquidity shocks appear to have played an extraordinary role during this period according to our historical decomposition analysis. Finally, we consider a subsample period from1983M1 to 2007M12, which excludes the Great Inflation and Great Recession.

Table 6 reports the results of the forecast error variance decomposition for the 1976M12018M12, 1973M1-2007M12, and 1983M1-2007M12 subsamples. We find that the impacts of illiquidity shocks on the macroeconomic variables are slightly amplified during the 1973M1-2007M12 subsample periods. The large variability of $I L R_{t}$ is accompanied with excessive volatilities in industrial production, employment, and inflation. This may result from the inclusion of the observations in the early 1970s (Great Inflation periods), but the overall conclusions regarding the importance of illiquidity shocks remain unchanged. As for the subsamples 1976M1-2018M12 and 1983M1-2007M12, it is obvious that the portion of forecast error variance attributable to illiquidity shocks is close to that using the full-sample periods (1973M1-2018M12). Hence, we conclude that the empirical findings using subsample periods are qualitatively similar to the benchmark results in Table 2.

\subsection{Asymmetric Effects of Illiquidity Shocks}

The macroeconomic effects of illiquidity shocks have been typically investigated using linear VARs. However, some recent studies suggest possible nonlinear properties of such shocks in different phases of the business cycle (Ellington, 2018; Ellington et al., 2017). These studies find that the relevance of illiquidity shocks is much larger during recessions than nonrecession periods. To shed light on the potential asymmetry property of illiquidity shocks during economic downturns, we follow Balke (2000) and consider a two-regime threshold vector autoregression (TVAR) as follows:

$$
Y_{t}=\mu^{1}+B^{1}(L) Y_{t-1}+\left(\mu^{2}+B^{2}(L) Y_{t-1}\right) I\left(\chi_{t-d}>\gamma\right)+D^{1} U_{t}+D^{2} I\left(\chi_{t-d}>\gamma\right) U_{t}
$$

where $Y_{t}$ is a vector containing all endogenous variables, $\mu^{1}$ and $\mu^{2}$ are denoted as intercepts, $B^{1}(L)$ and $B^{2}(L)$ are lag polynomial matrices associated with the two regimes, and 
$U_{t}$ is a vector of structural disturbances. The matrices $D^{1}$ and $D^{2}$ map the structural residuals to the reduced form residuals in both regimes. The variable $\chi_{t-d}$ denotes the threshold variable that determines the regime of the system, and $\gamma$ denotes the threshold value to be estimated. The integer $d$ is the lag length of the threshold variable. Typically, $d$ is unknown and must be estimated along with the other parameters. The indicator function $I\left(\chi_{t-d}>\gamma\right)$ equals 1 when $\chi_{t-d}>\gamma$, and 0 otherwise.

In (11), $\mu^{1}+\mu^{2}, B^{1}(L)+B^{2}(L), D^{1}+D^{2}$ are the parameters corresponding to the regime identified as $I\left(\chi_{t-d}>\gamma\right)=1$, while $\mu^{1}, D^{1}$ and $B^{1}(L)$ are the parameters for the regime $I\left(\chi_{t-d} \leq \gamma\right)=0$. We follow Balke (2000) to identify the shocks using a Cholesky decomposition on the variance-covariance matrix of the reduced form TVAR disturbances.

We specify a quarterly TVAR that includes seven endogenous variables: annual changes in the $\log$ of $I L R_{t}$ (which is defined as $\log I L R_{t}-\log I L R_{t-4}$ ), annual growth rates of $R G D P_{t}, C O N S_{t}, I N V_{t}, U E M P_{t}, C P I_{t}$, and the Federal funds rate. It is worth noting that except for the Federal funds rate, the other macroeconomic variables enter into the TVAR as growth rates, rather than levels. This is because the asymptotic properties of the TVAR estimators are generally established under the stationarity of the data (Tsay, 1998). Violating this assumption might lead to spurious nonlinearities and can invalidate the use of Hansen (1996)'s bootstrapping method for inference. We use a two-quarter moving average of the annual growth rate of $R G D P_{t}$ as the threshold variable, and $d$ lags. We set $d=1$, and the number of lag periods $p$ for the TVAR in equation (11) is two. The sample period is $1973 \mathrm{Q} 1$ to $2018 \mathrm{Q} 4$.

The estimated threshold value for the TVAR is presented in the Table 7 . The estimate of $\gamma$ is 0.02 , and we, thus, identify the periods with threshold value above and below it in the table as "high growth regime" or "low growth regime", respectively. To examine the threshold behavior of the TVAR model more specifically, we test a joint null hypothesis of $B^{2}(L)=0$ and $D^{2}=0$. To test for the existence of threshold effects, three Wald test statistics are computed: average (ave-Wald), exponential average (exp-Wald), and supremum (sup-Wald) Wald statistics. As shown in Table 7, all three statistics indicate that the threshold effect is significant at the $1 \%$ level.

We then analyze the regime-specific effect of illiquidity shocks by calculating the cumulative generalized impulse response functions of endogenous variables in the TVAR. 
14 We order the endogenous variables as the annual changes in $I L R_{t}$, annualized quarterly growth rates of $R G D P_{t}, C O N S_{t}, I N V_{t}, U E M P_{t}, C P I_{t}$, and the Federal funds rate, respectively. Figure 15 displays the cumulative responses of real GDP, consumption, investment, unemployment rate, and CPI inflation to a one-standard deviation illiquidity shock, conditional on a high growth boom or a low growth regime, respectively. We find that, in both regimes, an increase in stock market illiquidity leads to a fall in output, consumption, investment, inflation, and it causes the unemployment rate to rise. Furthermore, it is clear that a one-standard deviation increase in stock market illiquidity under the low growth regime causes these macroeconomic aggregates to fall to a much larger extent upon impact than under the high growth regime, especially before eight quarters. ${ }^{15}$ This finding supports the nonlinear effects of illiquidity shocks as documented by Ellington et al. (2017) and echoes Garcia and Schaller (2002)' findings that the impact of monetary shocks is stronger in recessionary periods than in normal times.

\section{$7 \quad$ Validation of Illiquidity Shocks}

\subsection{Comparing Illiquidity Shocks with Financial and Uncer- tainty Shocks}

The empirical results presented above indicate that the exogenous movements in stock market illiquidity are important drivers of economic fluctuations in the US. It is of interest to further examine whether stock market illiquidity is the source of business cycle fluctuations, or an endogenous response to other types of financial market disruptions, such as credit spreads and uncertainty proxies. These indicators of financial distress are commonly used to identify financial and uncertainty shocks in the literature (Caldara et al., 2016).

For this purpose, we consider a VAR with 11 endogenous variables (denoted VAR-11) to identify illiquidity shocks, financial shocks, and uncertainty shocks simultaneously. Our VAR-11 includes the excess bond premium developed by Gilchrist and Zakrajsek (2012),

\footnotetext{
${ }^{14}$ The details of the computation method of the generalized impulse response functions can be found in Balke (2000).

${ }^{15}$ Similar patterns can be found when using a two standard deviation illiquidity shock.
} 
which is measured by a residual component beyond the expected default risks of corporate bonds, and a measure of uncertainty a la Jurado et al. (2015) which is constructed using real economic data, and Amihud (2002)'s stock market illiquidity measure, together with the variables (2) to (9) labeled in Section 4.2. We use this 11-variable VAR to identify financial shocks (which are defined as exogenous movements in the excess bond premium), uncertainty shocks (exogenous movements in the uncertainty measure), and illiquidity shocks simultaneously by employing a standard recursive ordering on these 11 variables. We assume that $I L R_{t}$ is affected by the excess bond premium and the uncertainty proxy contemporaneously; that is, we order $I L R_{t}$ after the excess bond premium and the uncertainty proxy. This is a conservative approach to identifying illiquidity shocks because it implies that illiquidity shocks are residual shocks that are ordered after financial shocks and uncertainty shocks; however, all can affect $I L R_{t}$ contemporaneously. The idea behind this ordering is that the innovations in the excess bond premium have an immediate impact on the proxy of uncertainty, but the shocks to the uncertainty measure, i.e., "uncertainty shocks", are orthogonal to the current level of the excess bond premium. However, as documented by Caldara et al. (2016), the ordering of the excess bond premium and the uncertainty proxy matters when one identifies financial shocks and uncertainty shocks. Thus, we consider an alternative ordering by ordering the uncertainty proxy before the excess bond premium; that is, the innovations in the excess bond premium can only affect the uncertainty proxy with a one period lag, but the innovations in the uncertainty proxy can affect the excess bond premium immediately. We denote these two identification schemes as "EBP-UNC" and "UNC-EBP", respectively.

Following Caldara et al. (2016), we use the excess bond premium and Jurado et al. (2015)'s measure of uncertainty at the three-month forecast horizon to identify the financial and uncertainty shocks, respectively. The excess bond premium data and the macroeconomic uncertainty index are available at the websites of Board of Governors of the Federal Reserve System and Sydney Ludvigson. ${ }^{16}$ Figures 16, 17 and 18 display the impulse response functions of a one-standard deviation financial shock, uncertainty shock, and illiquidity shock under the EBP-UNC identification scheme. As shown in these fig-

\footnotetext{
${ }^{16}$ Excess bond premium can be downloaded at https ://www. federalreserve.gov/econresdata/notes/ feds-notes/2016/ecession-risk-and-the-excess-bond-premium-20160408.html, and Sydney Lud-
} vigson's website is https://www.sydneyludvigson.com/data-and-appendixes. 
ures, the identified financial and uncertainty shocks induce a notably persistent rise in the excess bond premium and Jurado et al. (2015)'s measure, and also generate a hump-shape and eventual persistent decline in industrial production, employment, and consumption. Both shocks also have an adverse effect on the stock market. In particular, an increase in the excess bond premium and uncertainty measure cause a sharp and immediate drop in the stock market index. We also find that the macroeconomic impact of illiquidity shocks is similar to that of illiquidity shocks identified by our benchmark VAR in terms of signs and persistence. However, the size of the impact is smaller. This result is unaffected when applying the UNC-EBP identification scheme. ${ }^{17}$ It is worth noting that, for both identification schemes, the impacts of financial shocks and uncertainty shocks on the illiquidity ratio are very small and statistically indistinguishable from zero. This suggests that Amihud (2002)'s illiquidity ratio is likely to be a distinct exogenous factor that affects the macroeconomy and financial market, rather than an endogenous shock absorber that reflects the disturbances from real economic activities and financial disruption. Finally, we find that illiquidity shocks affect the measure of uncertainty significantly at 10 months and beyond, which suggests that fluctuations in the measure of uncertainty proposed by Jurado et al. (2015) may arise endogenously in respond to illiquidity shocks at a longer horizon.

We further investigate this finding using a forecast error variance decomposition. Tables 8 and 9 report the fraction of the forecast error variance of excess bond premium, uncertainty proxy, and illiquidity ratio attributable to financial shocks, uncertainty shocks, and illiquidity shocks under the EBP-UNC and UNC-EBP identification schemes, respectively. At $k=24$ horizon, we find that illiquidity shocks explain around $17 \%$ of the variation in the uncertainty proxy for both identification schemes. This suggests that fluctuations in uncertainty partly reflect endogenous responses to stock market illiquidity. In sum, we conclude that stock market illiquidity is likely to be a source of macroeconomic fluctuations, and exogenous to financial and uncertainty shocks. While the movements in the uncertainty of macroeconomic activities are endogenous responses to adverse shocks related to financial market conditions, e.g., stock market illiquidity, this is consistent

\footnotetext{
${ }^{17}$ For brevity, the impulse response functions under the UNC-EBP identification scheme are reported in a supplementary appendix.
} 
with the argument in Caldara et al. (2016) that macroeconomic uncertainty is often an endogenous response to broader financial conditions.

\subsection{Comparing Illiquidity Shocks with Other Macroeconomic Shocks}

The empirical results presented in Section 7.1 indicate that stock market illiquidity is likely to be an exogenous factor that drives economic fluctuations, and it contributes to the variation in US business cycles beyond the financial shocks and uncertainty shocks.

We further examine the hypothesis that illiquidity shocks represent a distinct source of business cycle fluctuations, or whether such instability is caused by other types of shocks associated with business cycles, by checking the correlation between the identified illiquidity shocks and other economic shocks, which are external to our benchmark VAR system.

First, we compare illiquidity shocks with two measures of monetary policy shocks at a monthly frequency. The first monetary policy shock corresponds to Romer and Romer (2004)'s narrative methods and Greenbook forecasts (denoted as $\epsilon_{M, t}^{R R}$ ). In addition, we also consider Barakchian and Crowe (2013)'s monetary policy shocks, which are identified using high-frequency information from Fed funds futures (denoted as $\epsilon_{M, t}^{B C}$ ).

We also examine the correlations between illiquidity shocks and technology shocks at a quarterly frequency. The first set of technology shocks corresponds to unanticipated shocks to TFP, including the unanticipated TFP shocks identified in Ben Zeev and Khan (2015) and Justiniano et al. (2011) (denoted as $\epsilon_{T F P, t}^{B Z K}$ and $\epsilon_{T F P, t}^{J P T}$, respectively). The second set of technology shocks corresponds to news shocks about future technology changes, including news shocks about future TFP changes identified by Barsky and Sims (2011) (denoted as $\epsilon_{N E W S, t}^{B S-T F P}$ ) and news shocks about future investment-specific technology (IST) identified by Ben Zeev and Khan (2015) (denoted as $\epsilon_{N E W S, t}^{B Z K-I S T}$ ). ${ }^{18}$ The results in Table 10 show the correlations between illiquidity shocks and these external shocks. The illiquidity shocks implied by $I L R_{t}^{\text {Large }}$ and $I L R_{t}^{\text {Small }}$ are also used to calculate the correlations. We find that the correlations between illiquidity shocks and other external shocks range from

\footnotetext{
${ }^{18}$ The shock series data are obtained from Professor Valerie Ramey's website at https://econweb.ucsd.edu/ vramey/research.html
} 
-0.133 to 0.166 , which suggests that the contemporaneous relationship between illiquidity shocks and other macroeconomic shocks is very small. Hence, we conclude that our identified illiquidity shocks represent a distinct source of macroeconomic instability, and they are independent of other types of macroeconomic shocks.

\section{Conclusion}

In this paper, we examine the quantitative importance of stock market illiquidity shocks in the US. We show that illiquidity shocks lead to significant declines in industrial production, consumption, and employment, and the Federal funds rate falls in response to these adverse economic conditions. In addition, illiquidity shocks explain a significant portion of the variation in broad equity valuations.

Furthermore, using the historical decomposition approach proposed by Kilian (2009), we find that illiquidity shocks delineate the unfavorable movements in economic activity during recession periods exceptionally well. The cumulative effects of illiquidity shock were an important driver of the fall in investment and real GDP at the height of the 2008-2009 financial crisis period. They explain nearly $23.841 \%$ of the sharp increase in the unemployment rate in 2009 as well as the high and persistent unemployment rate in the subsequent "jobless recovery" period.

Our results demonstrate that the macroeconomic consequences of stock market illiquidity shocks are important. Thus, monetary authorities, which are generally responsible for maintaining and ensuring the overall stability of the economy and financial markets, should keep track of stock market liquidity when implementing monetary policy ex ante. Moreover, we find that the correlations between illiquidity shocks and other types of shocks are quite low, suggesting our identified illiquidity shocks represent a distinct source of macroeconomic instability. This demonstrates that illiquidity shocks, stemming from price impacts in the stock market, may contain information about economic conditions beyond traditional business cycle shocks in the literature.

While understanding the macroeconomic impacts of illiquidity shocks on macroeconomic variables is the main contribution of this study, several interesting extensions exist. For instance, it would be of interest to investigate the relationship between stock mar- 
ket illiquidity and macroeconomic variables using an identification strategy proposed by Rigobon (2003) and Rigobon and Sack (2003). In this way, we can also take into account the heteroskedasticity in the variance-covariance matrix of residuals in the VAR, when capturing the contemporaneous bidirectional causality between stock market illiquidity and other macroeconomic variables. We defer these issues to future research.

\section{References}

Amihud, Y. (2002), "Illiquidity and stock returns: Cross-section and time-series effects", Journal of Financial Markets, 5, 375-340.

- (2019), "Illiquidity and stock returns: A revisit", Critical Finance Review, 8, 1-19.

Balke, N. (2000), "Credit and economic activity: Credit regimes and nonlinear propagation of shocks", The Review of Economics and Statistics, 82, 344-349.

Barakchian, S.M. and Crowe, C. (2013), "Monetary policy matters: Evidence from new shocks", Journal of Monetary Economics, 60, 950-966.

Barsky, R. and Sims, E. (2011), "News shocks and business cycles", Journal of Monetary Economics, 58, 273-289.

Beaudry, P., Nam, D.-K., and Wang, J. (2011), "Do mood swings drive business cycles and is it rational?", NBER Working Papers 17651, National Bureau of Economic Research, Inc.

Ben Zeev, N. and Khan, H. (2015), "Investment-specific news shocks and U.S. business cycles", Journal of Money, Credit and Banking, 47, 1443-1464.

Bigio, S. (2015), "Endogenous liquidity and the business cycle", American Economic Review, 105, 1883-1927.

Bigio, S. and Schneider, A. (2017), "Liquidity shocks, business cycles and asset prices", European Economic Review, 97, 108-130.

Bloom, N. (2009), "The impact of uncertainty shocks", Econometrica, 77, 623-685.

Born, B., Breuer, S., and Elstner, S. (2018), "Uncertainty and the Great Recession", Oxford Bulletin of Economics and Statistics, 80, 951-971.

Brunnermeier, M. and Pedersen, L. (2009), "Market liquidity and funding liquidity", Review of Financial Studies, 22, 2201-2238. 
Caldara, D., Fuentes-Albero, C., Gilchrist, S., and Zakrajšek, E. (2016), "The macroeconomic impact of financial and uncertainty shocks", European Economic Review, 88, 185-207.

Chen, S.-S., Chou, Y.-H., and Yen, C.-Y. (2016), "Predicting US recessions with stock market illiquidity?", The B.E. Journal of Macroeconomics, 16, 93-123.

Chen, Y., Eaton, G., and Paye, B. (2018), "Micro(structure) before Macro? The predictive power of aggregate illiquidity for stock returns and economic activity", Journal of Financial Economics, 130, 48-73.

Chodorow-Reich, G. (2014), "The employment effects of credit market disruptions: Firmlevel evidence from the 2008-9 financial crisis", The Quarterly Journal of Economics, $129,1-59$.

Delikouras, S. and Kostakis, A. (2019), "A single-factor consumption-based asset pricing model", Journal of Financial and Quantitative Analysis, 54(2), 789-827.

DiCecio, R. (2009), "Sticky wages and sectoral labor comovement", Journal of Economic Dynamics and Control, 33, 538-553.

Ellington, M. (2018), "Financial market illiquidity shocks and macroeconomic dynamics: Evidence from the UK", Journal of Banking and Finance, 89, 225-236.

Ellington, M., Florackis, C., and Milas, C. (2017), "Liquidity shocks and real GDP growth: Evidence from a Bayesian time-varying parameter VAR", Journal of International Money and Finance, 72, 93-117.

Fernald, J. (2014), "A quarterly utilization-adjusted series on Total Factor Producticity", Federal Reserve Bank of San Francisco Working Paper Series.

Florackis, C., Giorgioni, G., Kostakis, A., and Milas, C. (2014), "On stock market illiquidity and real-time GDP growth", Journal of International Money and Finance, 44, $210-229$.

Francis, N., Owyang, M., Roush, J., and DiCecio, R. (2014), "A flexible finite-horizon alternative to long-run restriction with an application to technology shocks", Review of Economics and Statistics, 96, 638-647.

Garcia, R. and Schaller, H. (2002), "Are the effects of monetary policy asymmetric?", Economic Inquiry, 40, 102-119.

Gilchrist, S. and Zakrajsek, E. (2012), "Credit spreads and business cycle fluctuations", 
American Economic Review, 102, 1692-1720.

Goyenko, C., R. ad Holden and Trzcinka, C. (2009), "Do liquidity measures measure liquidity?", Journal of Financial Economics, 92, 153-181.

Goyenko, R. and Ukhov, A. (2009), "Stock and bond market liquidity: A long-run empirical analysis", Journal of Financial and Quantitative Analysis, 44, 189-212.

Hall, P. (1992), The bootstrap and Edgeworth expansion, New York: Springer.

Hansen, B. (1996), "Inference when a nuisance parameter is not identified under the null hypothesis", Econometrica, 63, 413-430.

Jurado, K., Sydney, L., and Ng, S. (2015), "Measuring uncertainty", American Economic Review, 105, 1177-1215.

Justiniano, A., Primiceri, G.E., and Tambalotti, A. (2011), "Investment shocks and the relative price of investment", Review of Economic Dynamics, 14, 102-121.

Katayama, M. and Kim, K.-H. (2018), "Uncertainty shocks and the relative price of investment goods", Review of Economic Dynamics, 30, 163-178.

Kilian, L. (2009), "Not all oil price shocks are alike: Disentangling demand and supply shocks in the crude oil market", American Economic Review, 99, 1053-1069.

Kiyotaki, N. and Moore, J. (2005), "Liquidity and asset prices", International Economic Review, 46, 317-349.

- (2019), "Liquidity, business cycles and monetary policy", Journal of Political Economy, 127, 2926-2966.

Kurmann, A. and Otrok, C. (2013), "News shocks and the slope of the term structure of interest rates", American Economic Review, 6, 2612-2632.

Lesmond, D., Ogden, J., and Trzcinka, C. (1999), "A new estimate of transaction costs", Review of Financial Studies, 12, 1113-1141.

Levine, R. (1991), "Stock markets, growth and tax policy", Journal of Finance, 46, 14451465 .

Levine, R. and Zervos, S. (1998), "Stock markets, banks, and economic growth", American Economic Review, 88, 537-558.

Longstaff, F. (2004), "The flight-to-quality premium in U.S. treasury bond prices", Journal of Business, 77, 511-525.

Næs, R., Skejeltorp, J., and Ødegaard, B. (2011), "Stock market liquidity and the business 
cycle", Journal of Finance, 66, 139-176.

Pastor, L. and Stambaugh, R. (2003), "Liquidity risk and expected stock returns", Journal of Political Economy, 111, 642-685.

Petrosky-Nadeau, N. and Wasmer, E. (2013), "The cyclical volatility of labor markets under frictional financial markets", American Economic Journal: Macroeconomics, 5(1), $193-221$.

(2015), "Macroeconomic dynamics in a model of goods, labor, and credit market frictions", Journal of Monetary Economics, 72, 97-113.

Rigobon, R. (2003), "Identification through heteroskedasticity", The Review of Economics and Statistics, 85, 777-792.

Rigobon, R. and Sack, B. (2003), "Measuring the reaction of monetary policy to the stock market", Quarterly Journal of Economics, 118, 639-669.

Roll, R. (1984), "A simple implicit measure of the effective bid-ask spread in an efficient market", Journal of Finance, 39, 1127-1139.

Romer, C.D. and Romer, D.H. (2004), "A new measure of monetary policy shocks: Derivation and implications", American Economic Review, 94, 1055-1084.

Shi, S-Y. (2015), "Liquidity, assets and business cycles", Journal of Monetary Economics, 70, 116-132.

Tsay, R. (1998), "Testing and modeling multivariate threshold models", Journal of the American Statistical Association, 93, 1188-1202.

Uhlig, H. (2003), "What drives GNP?", Unpublished.

— (2004), "Do technology shocks lead to a fall in total hours worked?", Journal of the European Economic Association, 2, 361-371.

Wu, J.C. and Xia, F.D. (2016), "Measuring the macroeconomic impact of monetary policy at the zero lower bound", Journal of Money, Credit and Banking, 48, 253-291. 
Table 1: Descriptive statistics of ILR

\begin{tabular}{lccc}
\hline & $I L R_{t}$ & $I L R_{t}^{\text {Large }}$ & $I L R_{t}^{\text {Small }}$ \\
\hline Mean & 0.017 & 0.001 & 0.047 \\
Median & 0.006 & 0.000 & 0.020 \\
Std.dev & 0.033 & 0.003 & 0.089 \\
No. of Sectors & 4697 & 1187 & 2538 \\
No. of Obs & 677,884 & 173,427 & 161,889 \\
\hline
\end{tabular}

Note: $I L R_{t}, I L R_{t}^{\text {Large }}, I L R_{t}^{\text {Small }}$ are illiquidity measures using data from all firms, large firms, and small firms, respectively. Std.dev denotes the standard deviation. The sample spans from 1973M1 to 2018M12. 
Table 2: Forecast Error Variance Decomposition of Illiquidity Shocks

\begin{tabular}{|c|c|c|c|c|c|}
\hline \multicolumn{6}{|c|}{ Forecast Error Variance Decomposition of ILR Shocks: $p=4$} \\
\hline & ILR & Industrial Production & Employment & PCE & PCE Deflator \\
\hline \multirow[t]{2}{*}{$k=1$} & 92.325 & 1.615 & 0.337 & 0.722 & 0.038 \\
\hline & {$[85.093,96.881]$} & {$[0.000,3.824]$} & {$[0.000,2.355]$} & {$[0.000,2.929]$} & {$[0.000,1.398]$} \\
\hline \multirow[t]{2}{*}{$k=6$} & 88.489 & 7.200 & 13.236 & 8.572 & 0.207 \\
\hline & {$[80.663,89.653]$} & {$[2.129,15.587]$} & {$[6.504,23.306]$} & {$[2.645,16.292]$} & {$[0.005,2.763]$} \\
\hline \multirow[t]{2}{*}{$k=12$} & 83.818 & 17.254 & 25.056 & 10.335 & 0.196 \\
\hline & {$[71.548,85.217]$} & {$[7.368,30.624]$} & {$[14.167,38.205]$} & {$[2.084,18.750]$} & {$[0.042,3.613]$} \\
\hline \multirow[t]{2}{*}{$k=24$} & 78.903 & 18.247 & 29.477 & 6.524 & 3.965 \\
\hline & {$[65.854,82.422]$} & {$[5.389,31.260]$} & {$[11.732,40.982]$} & {$[1.024,13.531]$} & {$[0.228,12.147]$} \\
\hline \multicolumn{6}{|c|}{ Forecast Error Variance Decomposition of ILR Shocks: $p=2$} \\
\hline \multirow[t]{2}{*}{$k=1$} & 95.479 & 0.001 & 0.363 & 0.522 & 0.327 \\
\hline & {$[90.925,98.523]$} & {$[0.000,0.920]$} & {$[0.000,2.129]$} & {$[0.000,1.758]$} & {$[0.000,1.947]$} \\
\hline \multirow[t]{2}{*}{$k=6$} & 93.198 & 14.051 & 14.891 & 6.227 & 0.245 \\
\hline & {$[87.364,95.286]$} & {$[7.251,22.442]$} & {$[8.167,23.331]$} & {$[1.380,11.085]$} & {$[0.002,2.345]$} \\
\hline \multirow[t]{2}{*}{$k=12$} & 88.051 & 26.798 & 29.292 & 8.276 & 0.264 \\
\hline & {$[78.243,91.840]$} & {$[14.586,37.491]$} & {$[17.335,40.066]$} & {$[0.851,14.214]$} & {$[0.017,3.097]$} \\
\hline \multirow[t]{2}{*}{$k=24$} & 84.473 & 25.996 & 31.640 & 5.764 & 3.917 \\
\hline & {$[73.840,89.186]$} & {$[10.713,37.255]$} & {$[15.237,43.114]$} & {$[0.452,11.676]$} & {$[0.023,10.378]$} \\
\hline
\end{tabular}

Note: The table reports the fraction of the variance in the $k$-step-ahead forecast error of the variable listed at the top of the table that is attributable to illiquidity shocks. Values in square brackets define the $90 \%$ bootstrap confidence intervals. Illiquidity shocks are identified using the MFEV method with $0<k<180$. 
Table 3: Forecast Error Variance Decomposition of Illiquidity Shocks: Large Firms versus Small Firms

\begin{tabular}{|c|c|c|c|c|c|}
\hline \multicolumn{6}{|c|}{ Forecast Error Variance Decomposition ILR Shocks: Large Firms } \\
\hline & ILR & Industrial Production & Employment & $\mathrm{PCE}$ & PCE Deflator \\
\hline \multirow[t]{2}{*}{$k=1$} & 91.273 & 1.821 & 0.320 & 0.051 & 0.035 \\
\hline & {$[83.043,96.165]$} & {$[0.000,4.163]$} & {$[0.000,1.964]$} & {$[0.000,1.191]$} & {$[0.000,1.462]$} \\
\hline \multirow[t]{2}{*}{$k=6$} & 90.571 & 3.621 & 7.160 & 4.191 & 0.794 \\
\hline & {$[82.576,91.472]$} & {$[1.140,8.822]$} & {$[1.491,13.752]$} & {$[0.502,9.536]$} & {$[0.007,4.401]$} \\
\hline \multirow[t]{2}{*}{$k=12$} & 86.576 & 13.642 & 19.211 & 5.506 & 0.674 \\
\hline & {$[73.894,87.897]$} & {$[5.205,25.886]$} & {$[7.913,30.377]$} & {$[0.331,12.146$} & {$[0.040,4.805]$} \\
\hline \multirow[t]{4}{*}{$k=24$} & 81.960 & 16.997 & 26.411 & 3.318 & 2.453 \\
\hline & {$[67.987,84.915]$} & {$[3.397,28.923]$} & {$[8.461,37.382]$} & {$[0.288,9.296]$} & {$[0.238,8.715]$} \\
\hline & Foreca & t Error Variance Decom & osition ILR Shock & : Small Firms & \\
\hline & ILR & Industrial Production & Employment & PCE & PCE Deflator \\
\hline \multirow{2}{*}{$k=1$} & 93.063 & 0.815 & 0.717 & 1.186 & 0.047 \\
\hline & {$[86.834,97.268]$} & {$[0.000,2.506]$} & {$[0.000,3.055]$} & {$[0.000,3.655]$} & {$[0.000,1.342]$} \\
\hline \multirow{2}{*}{$k=6$} & 88.031 & 9.341 & 15.423 & 9.302 & 0.103 \\
\hline & {$[79.784,88.800]$} & {$[3.807,19.042]$} & {$[8.017,25.394]$} & {$[3.278,17.000]$} & {$[0.008,2.312]$} \\
\hline \multirow[t]{2}{*}{$k=12$} & 83.133 & 19.269 & 26.631 & 10.385 & 0.245 \\
\hline & {$[71.189,84.569]$} & {$[8.910,32.424]$} & {$[15.614,39.586]$} & {$[2.573,18.808]$} & {$[0.019,3.759]$} \\
\hline \multirow[t]{2}{*}{$k=24$} & 78.488 & 18.970 & 29.467 & 6.223 & 4.828 \\
\hline & {$[65.817,81.810]$} & {$[5.833,31.442]$} & {$[12.976,41.757]$} & {$[1.151,12.822]$} & {$[0.368,13.496]$} \\
\hline
\end{tabular}

Note: The table reports the fraction of the variance in the $k$-step-ahead forecast error of the variable listed at the top of the table that is attributable to illiquidity shocks. Values in square brackets define the $90 \%$ bootstrap confidence intervals. Illiquidity shocks are identified by the MFEV method with $0<k<180$. 
Table 4: Historical Effects of Illiquidity Shocks to US Economic Activity

\begin{tabular}{|c|c|c|c|c|}
\hline \multicolumn{5}{|c|}{ Consumption Growth Rate } \\
\hline Year & Actual & Aggregate & Large Firms & Small Firms \\
\hline 2008 & $-3.173 \%$ & $0.099 \%$ & $0.014 \%$ & $0.068 \%$ \\
\hline 2009 & $-4.214 \%$ & $-1.382 \%$ & $-0.671 \%$ & $-1.339 \%$ \\
\hline 2010 & $-1.216 \%$ & $0.283 \%$ & $0.171 \%$ & $0.232 \%$ \\
\hline 2011 & $-1.074 \%$ & $0.496 \%$ & $0.301 \%$ & $0.484 \%$ \\
\hline 2012 & $-1.462 \%$ & $0.226 \%$ & $0.132 \%$ & $0.219 \%$ \\
\hline 2013 & $-1.512 \%$ & $0.072 \%$ & $0.090 \%$ & $0.057 \%$ \\
\hline 2014 & $-0.008 \%$ & $-0.221 \%$ & $-0.173 \%$ & $-0.224 \%$ \\
\hline 2015 & $0.728 \%$ & $-0.033 \%$ & $0.008 \%$ & $-0.043 \%$ \\
\hline 2016 & $-0.228 \%$ & $0.281 \%$ & $0.210 \%$ & $0.297 \%$ \\
\hline 2017 & $-0.357 \%$ & $0.317 \%$ & $0.195 \%$ & $0.317 \%$ \\
\hline 2018 & $0.040 \%$ & $0.153 \%$ & $0.091 \%$ & $0.144 \%$ \\
\hline \multicolumn{5}{|c|}{ Investment Growth Rate } \\
\hline Year & Actual & Aggregate & Large Firms & Small Firms \\
\hline 2008 & $-14.012 \%$ & $5.498 \%$ & $3.589 \%$ & $5.408 \%$ \\
\hline 2009 & $-28.621 \%$ & $-10.872 \%$ & $-4.809 \%$ & $-10.070 \%$ \\
\hline 2010 & $5.791 \%$ & $-0.557 \%$ & $-1.094 \%$ & $-0.944 \%$ \\
\hline 2011 & $1.033 \%$ & $1.896 \%$ & $1.065 \%$ & $1.864 \%$ \\
\hline 2012 & $5.907 \%$ & $0.869 \%$ & $0.128 \%$ & $0.928 \%$ \\
\hline 2013 & $1.097 \%$ & $1.177 \%$ & $1.430 \%$ & $1.165 \%$ \\
\hline 2014 & $1.025 \%$ & $-2.594 \%$ & $-1.805 \%$ & $-2.502 \%$ \\
\hline 2015 & $-0.696 \%$ & $-1.538 \%$ & $-1.532 \%$ & $-1.714 \%$ \\
\hline 2016 & $-8.048 \%$ & $0.258 \%$ & $0.083 \%$ & $0.273 \%$ \\
\hline 2017 & $-0.651 \%$ & $2.978 \%$ & $1.662 \%$ & $2.821 \%$ \\
\hline 2018 & $0.954 \%$ & $2.440 \%$ & $1.167 \%$ & $2.234 \%$ \\
\hline \multicolumn{5}{|c|}{ Unemployment Rate Growth Rate } \\
\hline Year & Actual & Aggregate & Large Firms & Small Firms \\
\hline 2008 & $26.871 \%$ & $-3.386 \%$ & $-1.520 \%$ & $-2.633 \%$ \\
\hline 2009 & $71.927 \%$ & $23.841 \%$ & $9.781 \%$ & $22.526 \%$ \\
\hline 2010 & $3.243 \%$ & $-5.862 \%$ & $-2.451 \%$ & $-4.680 \%$ \\
\hline 2011 & $-8.940 \%$ & $-6.831 \%$ & $-3.986 \%$ & $-6.512 \%$ \\
\hline 2012 & $-12.236 \%$ & $-3.545 \%$ & $-1.642 \%$ & $-3.630 \%$ \\
\hline 2013 & $-10.539 \%$ & $-1.570 \%$ & $-1.751 \%$ & $-1.330 \%$ \\
\hline 2014 & $-18.888 \%$ & $4.304 \%$ & $2.904 \%$ & $4.167 \%$ \\
\hline 2015 & $-16.278 \%$ & $0.455 \%$ & $0.073 \%$ & $0.672 \%$ \\
\hline 2016 & $-10.094 \%$ & $-4.098 \%$ & $-2.900 \%$ & $-4.308 \%$ \\
\hline 2017 & $-13.424 \%$ & $-5.648 \%$ & $-3.155 \%$ & $-5.496 \%$ \\
\hline 2018 & $-12.925 \%$ & $-2.528 \%$ & $-1.125 \%$ & $-2.444 \%$ \\
\hline \multicolumn{5}{|c|}{ Real GDP Growth Rate } \\
\hline Year & Actual & Aggregate & Large Firms & Small Firms \\
\hline 2008 & $-2.887 \%$ & $0.582 \%$ & $0.365 \%$ & $0.541 \%$ \\
\hline 2009 & $-5.280 \%$ & $-2.098 \%$ & $-1.002 \%$ & $-1.963 \%$ \\
\hline 2010 & $-0.196 \%$ & $0.381 \%$ & $0.177 \%$ & $0.299 \%$ \\
\hline 2011 & $-1.207 \%$ & $0.433 \%$ & $0.252 \%$ & $0.415 \%$ \\
\hline 2012 & $-0.507 \%$ & $0.241 \%$ & $0.097 \%$ & $0.244 \%$ \\
\hline 2013 & $-0.918 \%$ & $0.170 \%$ & $0.219 \%$ & $0.153 \%$ \\
\hline 2014 & $-0.237 \%$ & $-0.436 \%$ & $-0.342 \%$ & $-0.417 \%$ \\
\hline 2015 & $0.158 \%$ & $-0.110 \%$ & $-0.089 \%$ & $-0.137 \%$ \\
\hline 2016 & $-1.122 \%$ & $0.228 \%$ & $0.165 \%$ & $0.244 \%$ \\
\hline 2017 & $-0.391 \%$ & $0.516 \%$ & $0.312 \%$ & $0.492 \%$ \\
\hline 2018 & $0.169 \%$ & $0.291 \%$ & $0.134 \%$ & $0.267 \%$ \\
\hline
\end{tabular}

Note: The first column reports that the actual realizations of the growth rates are defined as the actual demeaned growth rates of $C O N S_{t}, I N V_{t}, U E M P_{t}$, and $R G D P_{t}$. The second to fourth columns report the growth effects of illiquidity shocks to annual growth rates of $C O N S_{t}, I N V_{t}, U E M P_{t}$, and $R G D P_{t}$. 
Table 5: Forecast Error Variance Decomposition of Illiquidity Shocks: Alternative Identification Schemes

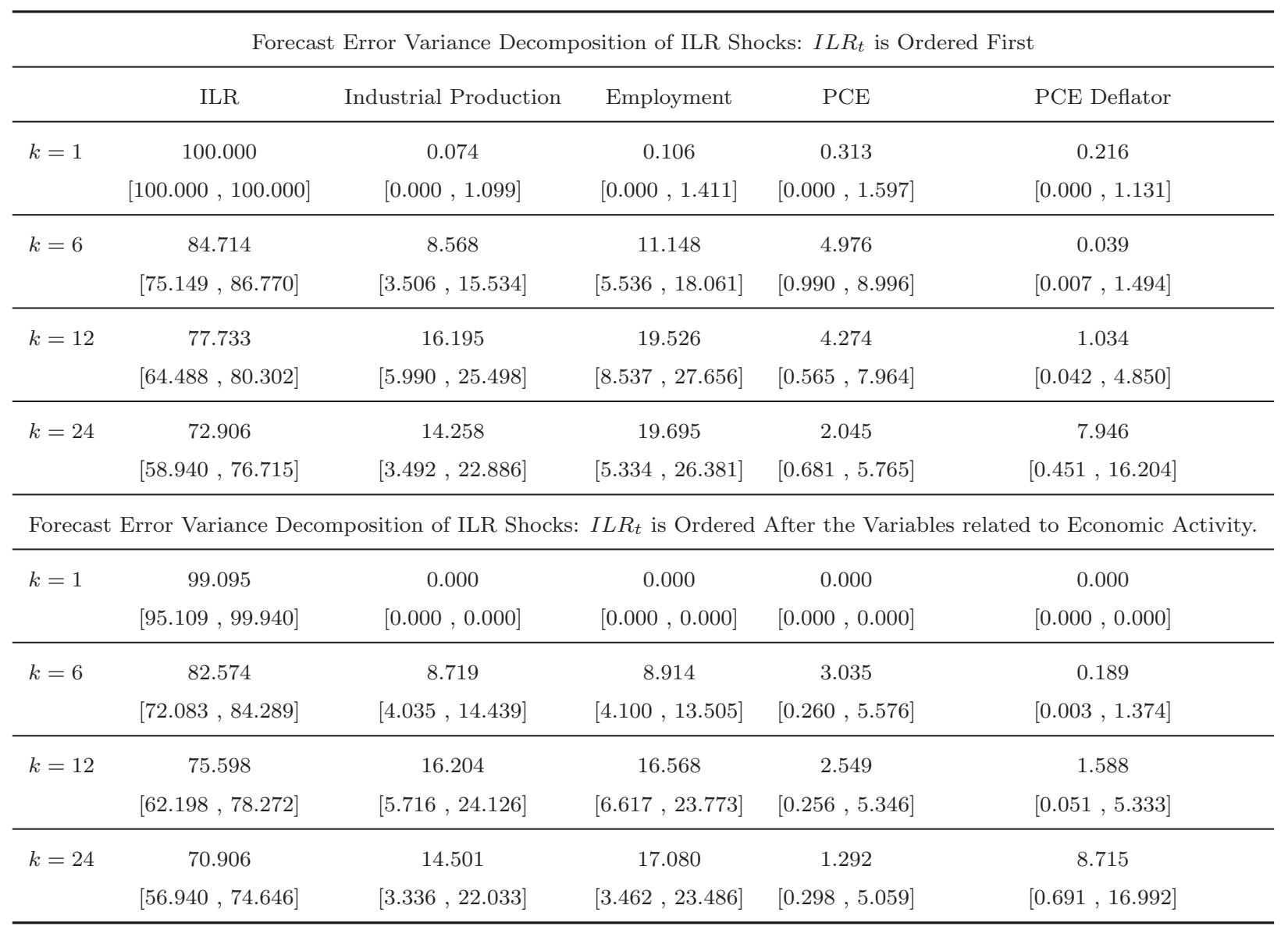

Note: The table reports the fraction of the variance in the $k$-step-ahead forecast error of the variable listed at the top of the table that is attributable to illiquidity shocks. Values in square brackets define the $90 \%$ bootstrap confidence intervals. Illiquidity shocks are identified by the Cholesky decomposition method rather than using the MFEV method. The ordering of the endogenous variables in the upper panel is (1) log of manufacturing industrial production index; (2) log of private employment; (3) log of real PCE; (4) $\log$ of PCE price deflator; (5) $I L R_{t}$; (6) log of S\&P GSCI; (7) log of real S\&P 500 Composite Stock Price Index; (8) nominal 10-year Treasury yield; (9) Federal funds rate, and the order of the endogenous variables in the lower panel is (1) log of manufacturing industrial production index; (2) log of private employment; (3) log of real PCE; (4) log of PCE price deflator; (5) $I L R_{t}$; (6) log of S\&P GSCI; (7) log of real S\&P 500 Composite Stock Price Index; (8) nominal 10-year Treasury yield; (9) Federal funds rate. 
Table 6: Forecast Error Variance Decomposition of Illiquidity Shocks: Subsample Analysis

\begin{tabular}{|c|c|c|c|c|c|}
\hline \multicolumn{6}{|c|}{ Forecast Error Variance Decomposition of ILR Shocks: 1976M1 to 2018M12 } \\
\hline & ILR & Industrial Production & Employment & PCE & PCE Deflator \\
\hline \multirow{2}{*}{$k=1$} & 97.082 & 1.460 & 2.444 & 4.543 & 0.705 \\
\hline & {$[94.731,99.126]$} & {$[0.000,5.024]$} & {$[0.000,6.026]$} & {$[1.142,9.929]$} & {$[0.000,2.867]$} \\
\hline \multirow[t]{2}{*}{$k=6$} & 90.407 & 18.381 & 12.729 & 16.572 & 0.048 \\
\hline & {$[81.814,91.552]$} & {$[8.774,29.049]$} & {$[4.124,21.164]$} & {$[7.894,24.829]$} & {$[0.014,2.553]$} \\
\hline \multirow[t]{2}{*}{$k=12$} & 88.228 & 22.835 & 18.088 & 18.171 & 0.085 \\
\hline & {$[77.815,88.978]$} & {$[8.885,34.041]$} & {$[5.469,27.690]$} & {$[6.101,26.015]$} & {$[0.011,3.822]$} \\
\hline \multirow[t]{3}{*}{$k=24$} & 86.650 & 17.974 & 15.150 & 12.563 & 1.284 \\
\hline & {$[75.595,87.261]$} & {$[4.796,28.130]$} & {$[2.256,22.343]$} & {$[2.434,20.046]$} & {$[0.032,6.805]$} \\
\hline & Forecast Er & or Variance Decomposit & n of ILR Shocks: & $973 \mathrm{M} 1$ to $2007 \mathrm{M} 1$ & \\
\hline \multirow{2}{*}{$k=1$} & 94.283 & 1.587 & 0.019 & 0.334 & 0.250 \\
\hline & {$[88.152,98.313]$} & {$[0.000,3.402]$} & {$[0.000,1.711]$} & {$[0.000,2.131]$} & {$[0.000,2.358]$} \\
\hline \multirow{2}{*}{$k=6$} & 91.126 & 12.360 & 11.941 & 7.785 & 0.252 \\
\hline & {$[81.686,91.838]$} & {$[6.548,24.554]$} & {$[5.092,23.551]$} & {$[1.474,13.811]$} & {$[0.004,3.380]$} \\
\hline \multirow{2}{*}{$k=12$} & 87.639 & 33.278 & 32.569 & 11.739 & 0.390 \\
\hline & {$[73.570,88.448]$} & {$[20.120,48.002]$} & {$[19.574,48.012]$} & {$[1.361,18.527]$} & {$[0.019,5.192]$} \\
\hline \multirow[t]{3}{*}{$k=24$} & 83.408 & 37.271 & 44.050 & 8.153 & 4.951 \\
\hline & {$[68.260,85.456]$} & {$[15.650,48.202]$} & {$[21.839,56.985]$} & {$[1.064,15.144]$} & {$[0.022,15.357]$} \\
\hline & Forecast Er & or Variance Decomposit & on of ILR Shocks: & $983 \mathrm{M} 1$ to $2007 \mathrm{M} 1$ & \\
\hline \multirow[t]{2}{*}{$k=1$} & 90.405 & 0.254 & 0.019 & 0.034 & 3.139 \\
\hline & {$[80.251,97.666]$} & {$[0.000,5.624]$} & {$[0.000,8.680]$} & {$[0.000,5.236]$} & {$[0.000,13.209]$} \\
\hline \multirow[t]{2}{*}{$k=6$} & 89.803 & 6.902 & 2.505 & 9.117 & 8.262 \\
\hline & {$[75.493,90.803]$} & {$[0.659,21.476]$} & {$[0.032,11.862]$} & {$[2.236,21.813]$} & {$[0.067,21.230]$} \\
\hline \multirow[t]{2}{*}{$k=12$} & 85.890 & 15.210 & 8.834 & 21.467 & 9.476 \\
\hline & {$[67.464,86.219]$} & {$[2.279,34.557]$} & {$[0.190,22.939]$} & {$[6.134,35.663]$} & {$[0.147,22.458]$} \\
\hline \multirow[t]{2}{*}{$k=24$} & 83.429 & 21.518 & 18.618 & 26.747 & 9.301 \\
\hline & {$[64.103,84.216]$} & {$[2.788,38.941]$} & {$[1.123,33.982]$} & {$[6.309,42.635]$} & {$[0.070,21.233]$} \\
\hline
\end{tabular}

Note: The table reports the fraction of the variance in the $k$-step-ahead forecast error of the variable listed at the top of the table that is attributable to illiquidity shocks. Values in square brackets define the $90 \%$ bootstrap confidence intervals. All VARs are identified using the MFEV method with $0<k<180$. 
Table 7: Estimated Threshold Value, and Test for TVAR

\begin{tabular}{lcc}
\hline Estimated Threshold: $\gamma=0.02$ & & \\
\hline Test statistics & Value & p-value \\
\hline sup-Wald & 299.80 & 0.000 \\
avg-Wald & 244.15 & 0.000 \\
exp-Wald & 145.51 & 0.000 \\
\hline
\end{tabular}

The $p$-values are obtained using Hansen (1996)'s bootstrapping method. 
Table 8: Forecast Error Variance Decomposition of Financial Shocks, Uncertainty Shocks, and Illiquidity Shocks: EBP-UNC Identification Scheme

\begin{tabular}{|c|c|c|c|c|}
\hline \multicolumn{5}{|c|}{ Forecast Error Variance Decomposition: $E B P_{t}$ is Ordered Before $U N C_{t}$} \\
\hline & & $E B P_{t}$ & $U N C_{t}$ & $I L R_{t}$ \\
\hline \multirow[t]{8}{*}{ Financial Shock } & $k=1$ & 100.000 & 0.804 & 0.275 \\
\hline & & {$[100.000,100.000]$} & {$[0.000,2.913]$} & {$[0.000,1.401]$} \\
\hline & $k=6$ & 85.920 & 3.646 & 3.426 \\
\hline & & {$[74.798,89.397]$} & {$[0.011,7.927]$} & {$[0.629,7.042]$} \\
\hline & $k=12$ & 75.212 & 4.087 & 3.460 \\
\hline & & {$[59.592,80.960]$} & {$[0.023,9.167]$} & {$[0.947,7.759]$} \\
\hline & $k=24$ & 67.096 & 4.022 & 3.428 \\
\hline & & {$[50.155,71.117]$} & {$[1.238,10.624]$} & {$[1.324,8.593]$} \\
\hline \multirow[t]{8}{*}{ Uncertainty Shocks } & $k=1$ & 0.000 & 99.196 & 0.002 \\
\hline & & {$[0.000,0.000]$} & {$[97.087,100.000]$} & {$[0.000,1.120]$} \\
\hline & $k=6$ & 9.247 & 89.566 & 2.300 \\
\hline & & {$[3.355,15.315]$} & {$[79.644,92.961]$} & {$[0.449,5.383]$} \\
\hline & $k=12$ & 14.579 & 76.778 & 2.033 \\
\hline & & {$[3.971,21.269]$} & {$[57.519,81.201]$} & {$[0.550,5.494]$} \\
\hline & $k=24$ & 14.114 & 58.300 & 1.947 \\
\hline & & {$[4.168,19.928]$} & {$[38.314,65.576]$} & {$[0.892,6.191]$} \\
\hline \multirow[t]{8}{*}{ Illiquidity Shocks } & $k=1$ & 0.000 & 0.000 & 99.724 \\
\hline & & {$[0.000,0.000]$} & {$[0.000,0.000]$} & {$[97.547,100.000]$} \\
\hline & $k=6$ & 0.133 & 0.238 & 82.964 \\
\hline & & {$[0.034,1.382]$} & {$[0.002,1.630]$} & {$[71.859,84.072]$} \\
\hline & $k=12$ & 0.422 & 3.282 & 76.595 \\
\hline & & {$[0.049,3.465]$} & {$[0.012,8.964]$} & {$[62.527,78.325]$} \\
\hline & $k=24$ & 1.974 & 17.078 & 71.396 \\
\hline & & {$[0.153,6.892]$} & {$[5.087,26.583]$} & {$[56.515,73.806]$} \\
\hline
\end{tabular}

Note: The table reports the fraction of the variance in the $k$-step-ahead forecast error of the variable listed at the top of the table that is attributable to illiquidity shocks. Values in square brackets define the $90 \%$ bootstrap confidence intervals. The VAR is identified using the Cholesky decomposition method, and the ordering of the endogenous variables is (1) excess bond premium; (2) Jurado et al. (2015)'s measure of macroeconomic uncertainty; (3) ILR $R_{t}$ (4) log of manufacturing industrial production index; (5) log of private employment; (6) log of real PCE; (7) log of PCE price deflator; (8) Federal funds rate; (9) nominal 10-year Treasury yield; (10) log of real S\&P 500 Composite Stock Price Index; and (11) log of S\&P GSCI. 
Table 9: Forecast Error Variance Decomposition of Financial Shocks, Uncertainty Shocks, and Illiquidity Shocks: UNC-EBP Identification Scheme

\begin{tabular}{|c|c|c|c|c|}
\hline \multicolumn{5}{|c|}{ Forecast Error Variance Decomposition: UNC-EBP Identification Scheme } \\
\hline & & $E B P_{t}$ & $U N C_{t}$ & $I L R_{t}$ \\
\hline \multirow[t]{8}{*}{ Financial Shocks } & $k=1$ & 99.196 & 0.000 & 0.276 \\
\hline & & {$[97.087,100.000]$} & {$[0.000,0.000]$} & {$[0.000,1.255]$} \\
\hline & $k=6$ & 81.565 & 1.155 & 2.953 \\
\hline & & {$[69.972,86.497]$} & {$[0.001,3.213]$} & {$[0.530,6.293]$} \\
\hline & $k=12$ & 70.266 & 1.562 & 3.028 \\
\hline & & {$[53.975,75.413]$} & {$[0.023,5.030]$} & {$[0.883,7.160]$} \\
\hline & $k=24$ & 62.705 & 2.488 & 3.042 \\
\hline & & {$[46.177,67.461]$} & {$[0.612,8.216]$} & {$[0.866,7.660]$} \\
\hline \multirow[t]{8}{*}{ Uncertainty Shocks } & $k=1$ & 0.804 & 100.000 & 0.000 \\
\hline & & {$[0.000,2.913]$} & {$[100.000,100.000]$} & {$[0.000,1.270]$} \\
\hline & $k=6$ & 13.602 & 92.057 & 2.773 \\
\hline & & {$[6.203,21.087]$} & {$[83.467,94.414]$} & {$[0.607,6.314]$} \\
\hline & $k=12$ & 19.525 & 79.303 & 2.465 \\
\hline & & {$[8.184,26.961]$} & {$[61.203,83.974]$} & {$[0.686,6.374]$} \\
\hline & $k=24$ & 18.505 & 59.835 & 2.334 \\
\hline & & {$[7.177,24.404]$} & {$[38.879,66.126]$} & {$[0.976,6.836]$} \\
\hline \multirow[t]{8}{*}{ Illiquidity Shocks } & $k=1$ & 0.000 & 0.000 & 99.724 \\
\hline & & {$[0.000,0.000]$} & {$[0.000,0.000]$} & {$[97.547,100.000]$} \\
\hline & $k=6$ & 0.133 & 0.238 & 82.964 \\
\hline & & {$[0.034,1.382]$} & {$[0.002,1.630]$} & {$[71.859,84.072]$} \\
\hline & $k=12$ & 0.422 & 3.282 & 76.595 \\
\hline & & {$[0.049,3.465]$} & {$[0.012,8.964]$} & {$[62.527,78.325]$} \\
\hline & $k=24$ & 1.974 & 17.078 & 71.396 \\
\hline & & {$[0.153,6.892]$} & {$[5.078,26.583]$} & {$[56.515,76.806]$} \\
\hline
\end{tabular}

Note: The table reports the fraction of the variance in the $k$-step-ahead forecast error of the variable listed at the top of the table that is attributable to illiquidity shocks. Values in square brackets define the $90 \%$ bootstrap confidence intervals. The VAR is identified using the Cholesky decomposition method, and the ordering of the endogenous variables is (1) Jurado et al. (2015)'s measure of macroeconomic uncertainty; (2) excess bond premium; (3) $I L R_{t}$; (4) log of manufacturing industrial production index; (5) log of private employment; (6) log of real PCE; (7) log of PCE price deflator; (8) Federal funds rate; (9) nominal 10-year Treasury yield; (10) log of real S\&P 500 Composite Stock Price Index; and (11) log of S\&P GSCI. 
Table 10: Correlations with Other Shocks

\begin{tabular}{lccc}
\hline \multicolumn{4}{c}{ Monthly Shocks } \\
\hline Monetary Shocks & Aggregate ILR Shocks & ILR Shocks (Large Firms) & ILR Shocks (Small Firms) \\
\hline$\epsilon_{M, t}^{R R}$ & 0.149 & 0.125 & 0.143 \\
$\epsilon_{M, t}^{B C}$ & 0.155 & 0.166 & 0.125 \\
\hline \multicolumn{4}{c}{ Quarterly Shocks } \\
\hline Unanticipated TFP Shocks & Aggregate ILR Shocks & ILR Shocks (Large Firms) & ILR Shocks (Small Firms) \\
\hline$\epsilon_{T F P, t}^{B Z K}$ & -0.005 & -0.052 & 0.005 \\
$\epsilon_{T F P, t}^{J P T}$ & 0.013 & -0.059 & 0.027 \\
\hline News Shocks & Aggregate ILR Shocks & ILR Shocks (Large Firms) & ILR Shocks (Small Firms) \\
\hline$\epsilon_{N E W S, t}^{B S-T F P}$ & -0.133 & -0.074 & -0.127 \\
$\epsilon_{N E W S, t}^{B P-I S T}$ & -0.006 & 0.016 & -0.020 \\
\hline
\end{tabular}

The data of the shock series can be downloaded at Professor Valerie Ramey's website.

Abbreviations: $\epsilon_{M, t}^{R R}$ : Romer and Romer (2004)'s narrative methods and Greenbook forecasts (1973M1-2007M12).

$\epsilon_{M, t}^{B C}$ : Barakchian and Crowe (2013)'s monetary policy shocks, which are identified using high-frequency information from Fed funds futures (1988M12-2008M6).

$\epsilon_{T F P, t}^{B Z K}$ : unanticipated TFP shocks in Ben Zeev and Khan (2015) (1973Q1-2012Q1).

$\epsilon_{T F P, t}^{J P T}$ : unanticipated TFP shocks in Justiniano et al. (2011) (1973Q1-2009Q1).

$\epsilon_{N E W S, t}^{B S-T F P}:$ TFP news shocks in Barsky and Sims (2011) (1973Q1-2007Q3).

$\epsilon_{N E W S, t}^{B Z K K-I S T}$ : IST news shocks in Ben Zeev and Khan (2015) (1973Q1-2012Q1). 
Figure 1: Historical Effects of Illiquidity Shocks to Economic Activity: Shock implied by $I L R_{t}$
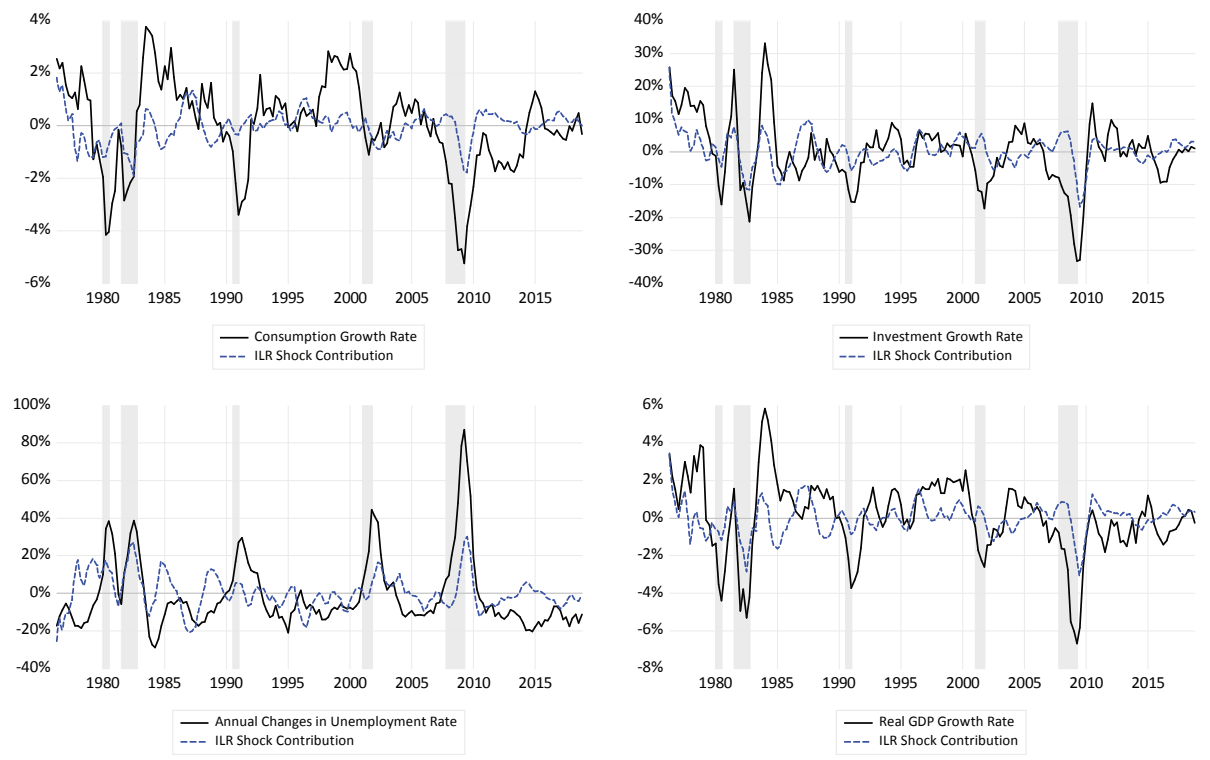

Note: The black solid lines are the actual growth rates of real economic activity $X_{t}, X_{t}=C O N S_{t}, I N V_{t}, U E M P_{t}$, andRGDPt. The blue dashed lines are the historical effects of illiquidity shocks. Historical decompositions are implemented by estimating the regression $Z_{t}=c+\sum_{i=0}^{12} \phi_{i} \hat{\zeta}_{I L R, t-i}+\epsilon_{t}$, where $c$ denotes a constant, and $Z_{t}=\left(X_{t}-X_{t-4}\right) / X_{t-4}$ denotes the annualized growth rate of a quarterly measure of real economic activity $X_{t}$, and $\hat{\zeta}_{I L R, t}$ is quarterly average monthly illiquidity shocks obtained from the benchmark VAR. The predicted historical values $\hat{Z}_{t} \equiv \hat{c}+\sum_{i=0}^{12} \hat{\phi}_{i} \hat{\zeta}_{I L R, t-i}$ enable us to study the portion of the change in real economic activity that is attributable to illiquidity shocks over the sample period. 
Figure 2: Plots of Forecast Error Variance Decomposition implied by $I L R_{t}$
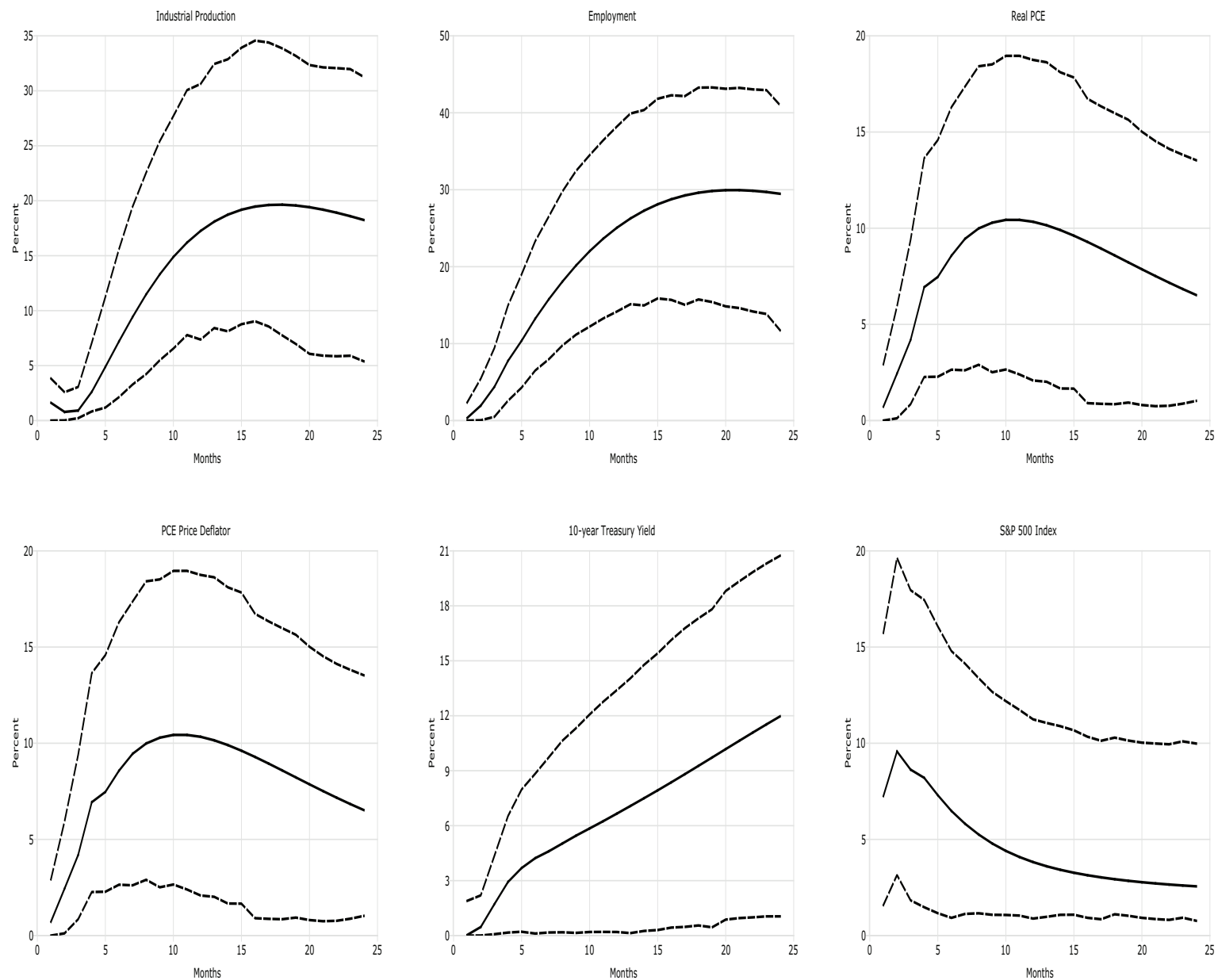

Note: The solid lines are the portion of the forecast error variance explained by illiquidity shocks identified by the MFEV method with $0<k<180$, while the dashed lines are $90 \%$ bootstrapped confidence intervals. 
Figure 3: Plots of Amihud's Monthly Illiquidity Measures. Shaded Areas Represent NBER Recession Dates.
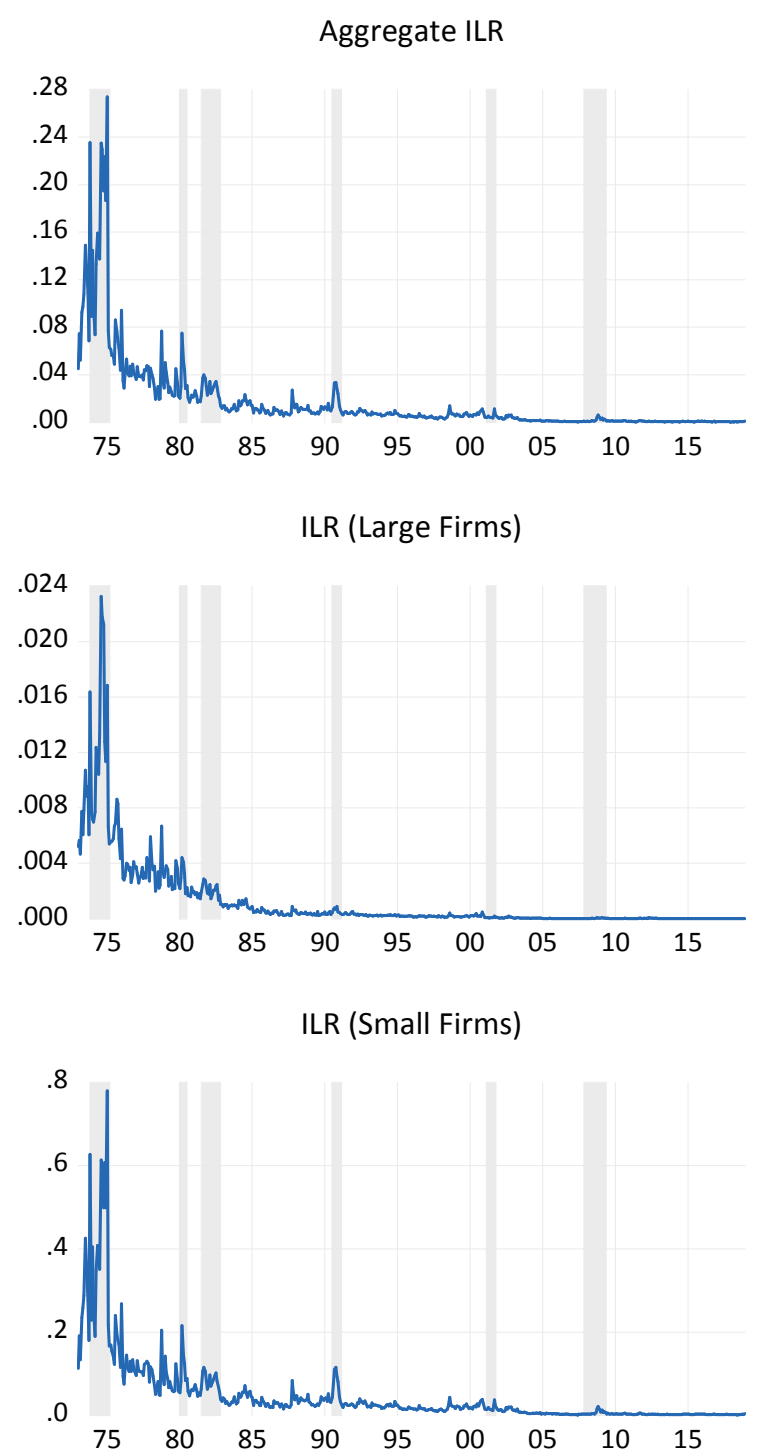

Note: The sample periods of $I L R_{t}, I L R_{t}^{\text {Large }}$, and $I L R_{t}^{\text {Small }}$ are $1973 \mathrm{M} 1-2018 \mathrm{M} 12$. 
Figure 4: Plots of Annual Changes in Illiquidity Measures. Shaded Areas Represent NBER Recession Dates.

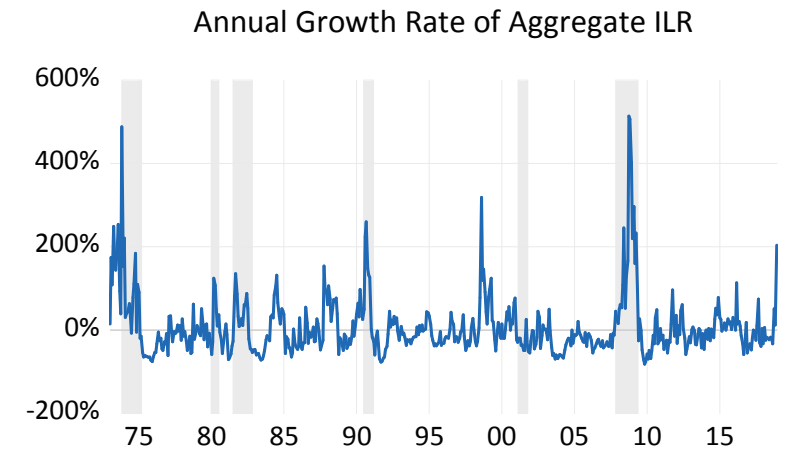

Annual Growth Rate of ILR (Large Firms)

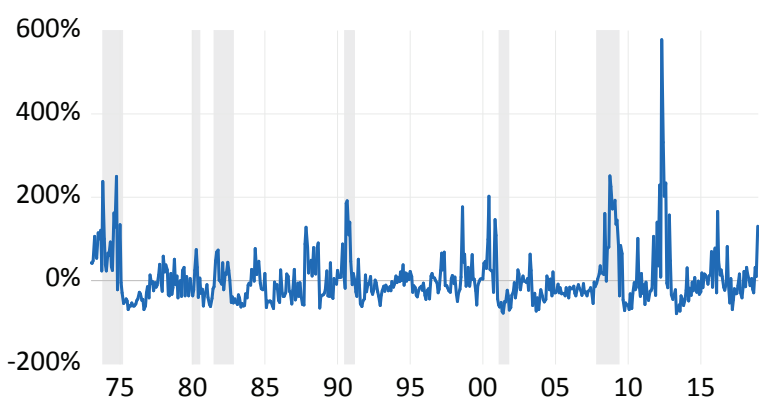

Annual Growth Rate of ILR (Small Firms)

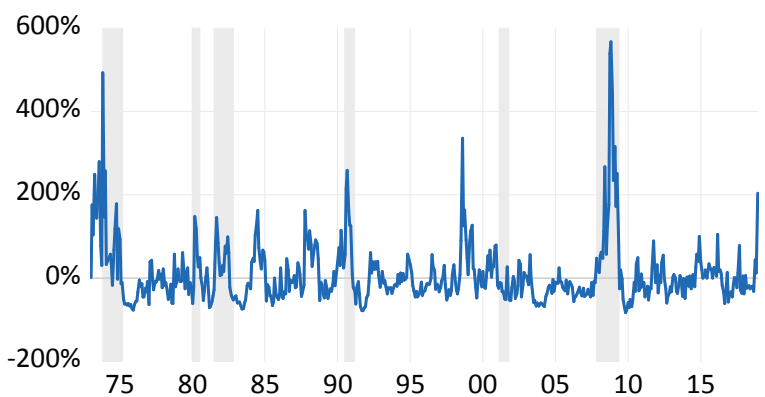

Note: The annual changes in illiquidity measures $I L R_{t}, I L R_{t}^{\text {Large }}, I L R_{t}^{\text {Small }}$ are computed by $\left(I L R_{t}-I L R_{t-12}\right) / I L R_{t-12},\left(I L R_{t}^{\text {Large }}-\right.$ $\left.I L R_{t-12}^{\text {Large }}\right) / I L R_{t-12}^{\text {Large }}$ and $\left(I L R_{t}^{\text {Small }}-I L R_{t-12}^{\text {Small }}\right) / I L R_{t-12}^{\text {Small }}$, respectively. 
Figure 5: Impulse Response Function of a One-Standard-Deviation Illiquidity Shock from the Benchmark VAR
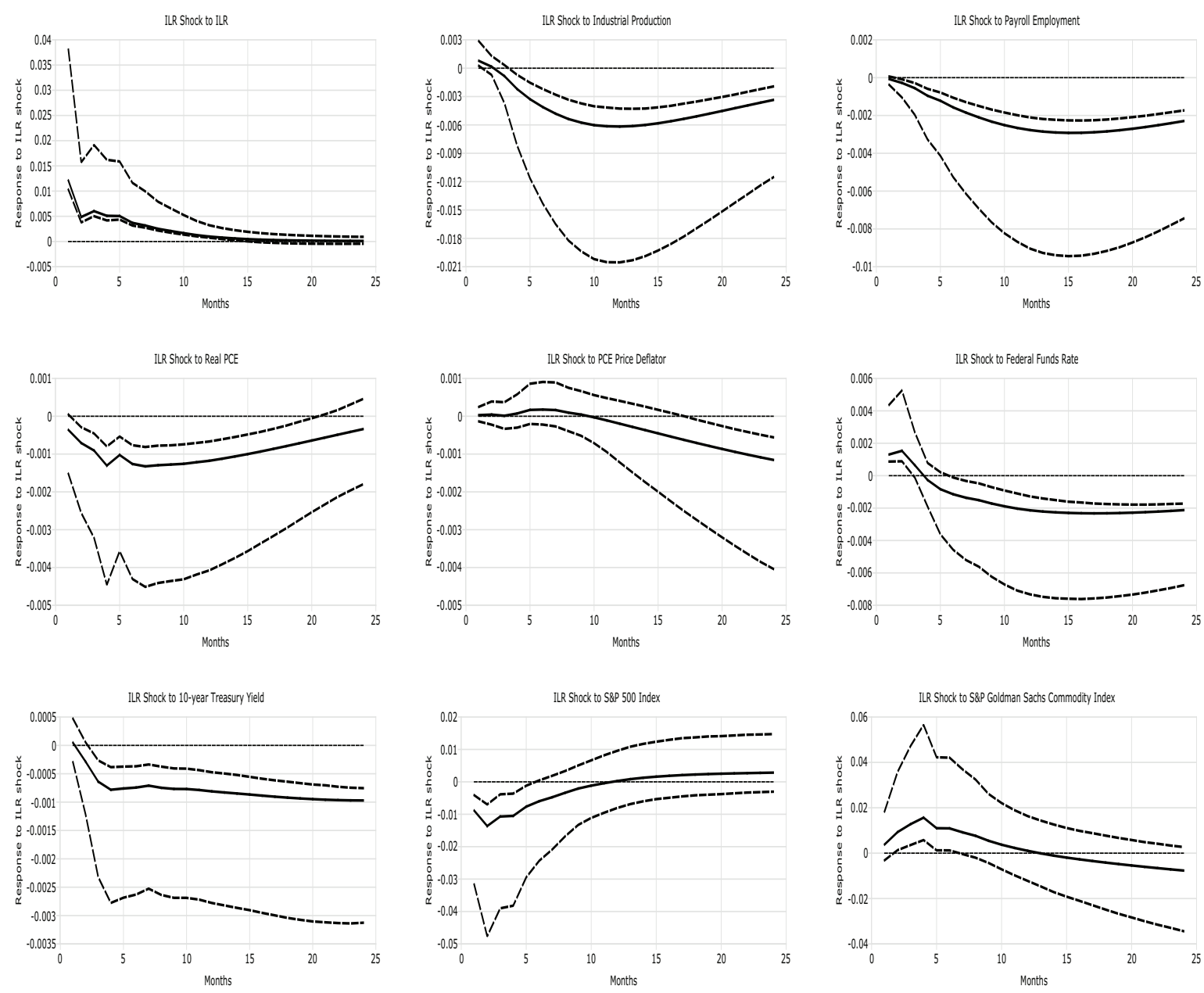

Note: The dashed lines represents the $90 \%$ bootstrapped confidence intervals. The VAR is identified using the MFEV method with $0<k<180$ 
Figure 6: Impulse Response Function of a One-Standard-Deviation Illiquidity Shock from the Benchmark VAR: Shock implied by $I L R_{t}, I L R_{t}^{\text {Large }}$, and $I L R_{t}^{\text {Small }}$
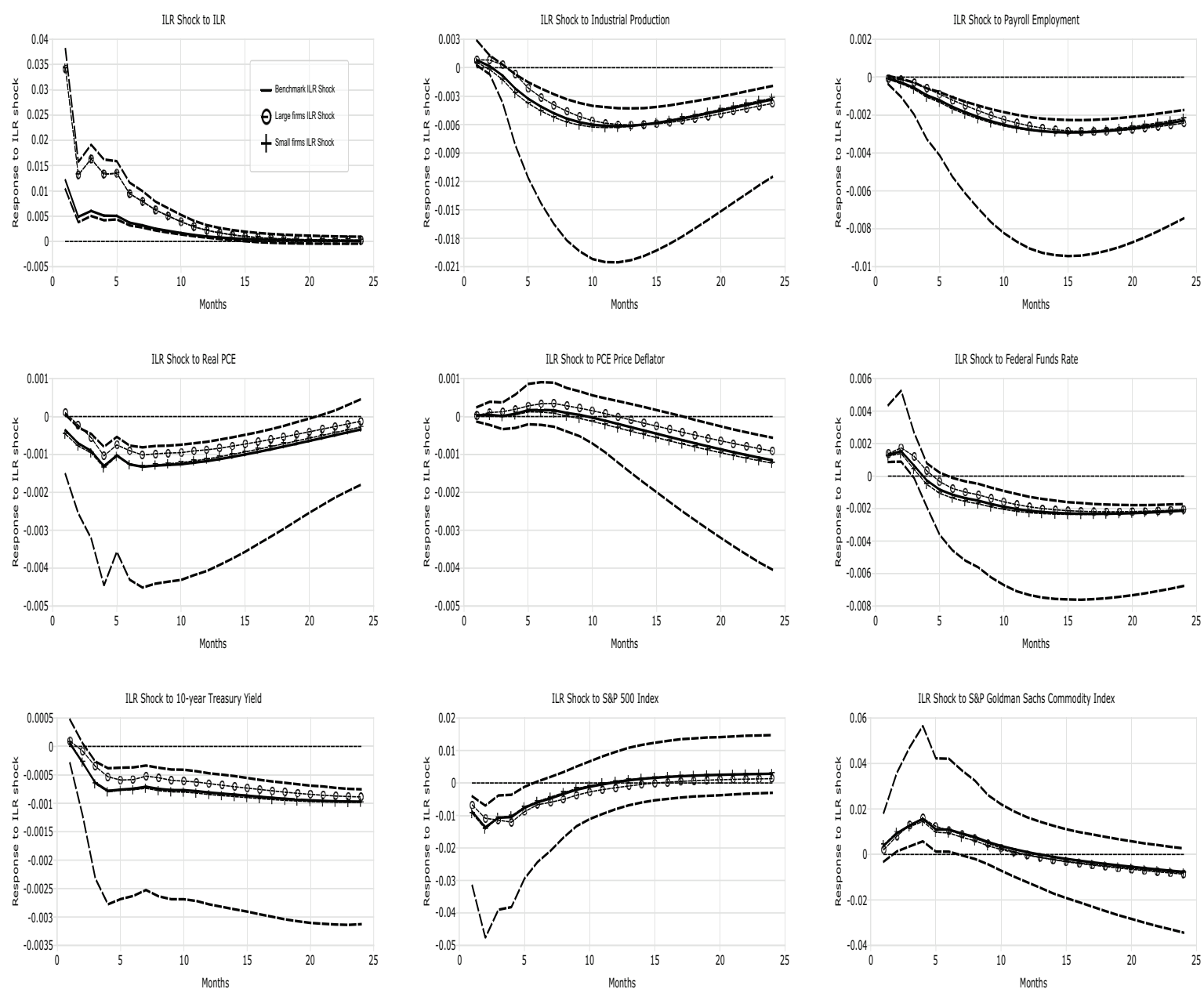

Note: The dashed lines are $90 \%$ bootstrapped confidence intervals in our benchmark VAR using aggregate $I L R_{t}$. The dashed lines with dot symbols are impulse response functions computed from $I L R_{t}^{\text {Large }}$, while the dashed lines with cross symbols are impulse response functions computed from $I L R_{t}^{\text {Small }}$, respectively. The VARs are identified using the MFEV method with $0<k<180$. 
Figure 7: Historical Effects of Illiquidity Shocks on Economic Activity: Shock implied by $I L R_{t}^{\text {Large }}$ and $I L R_{t}^{\text {Small }}$
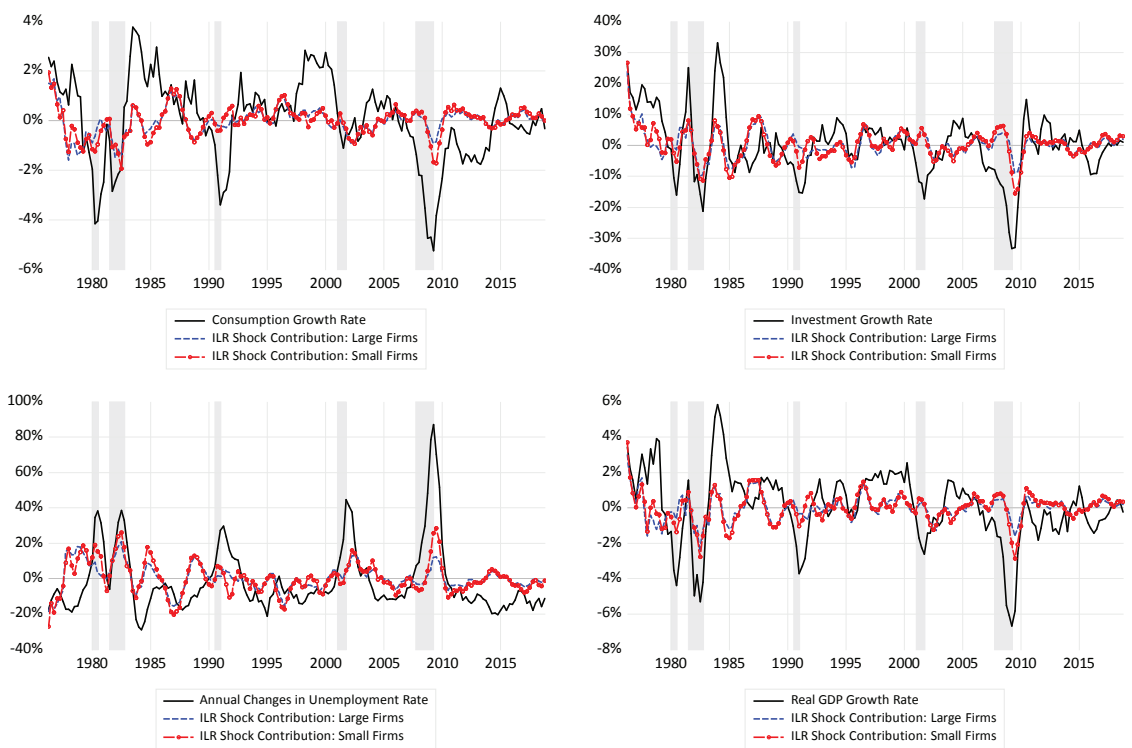

Note: The black solid lines are the actual growth rates of real economic activity $X_{t}, X_{t}=C O N S_{t}, I N V_{t}, U E M P_{t}$, andRGDP. The blue dashed lines are the historical effects of illiquidity shocks implied by $I L R_{t}^{L a r g e}$, and the red dashed lines with dot symbols are the historical effects of illiquidity shocks implied by $I L R_{t}^{S m a l l}$. The historical decomposition method is implemented by estimating the regression $Z_{t}=c+\sum_{i=0}^{12} \phi_{i} \hat{\zeta}_{I L R, t-i}^{j}+\epsilon_{t}, j=$ Large, Small, where $c$ denotes a constant, and $Z_{t}=\left(X_{t}-X_{t-4}\right) / X_{t-4}$ denotes the annualized growth rate of a quarterly measure of real economic activity $X_{t} \cdot \hat{\zeta}_{I L R, t}^{j}$ is denoted as the quarterly average monthly illiquidity shocks obtained from the benchmark VAR. The predicted historical values $\hat{Z}_{t} \equiv \hat{c}+\sum_{i=0}^{12} \hat{\phi}_{i} \hat{\zeta}_{I L R, t-i}^{j}, j=$ Large,Small enable us to study the portion of the change in real economic activity that is attributable to illiquidity shocks over the sample period. 
Figure 8: Impulse Response Function of a One-Standard-Deviation Illiquidity Shock from the VAR with Recursive Identification Scheme: $I L R_{t}$ is Ordered First
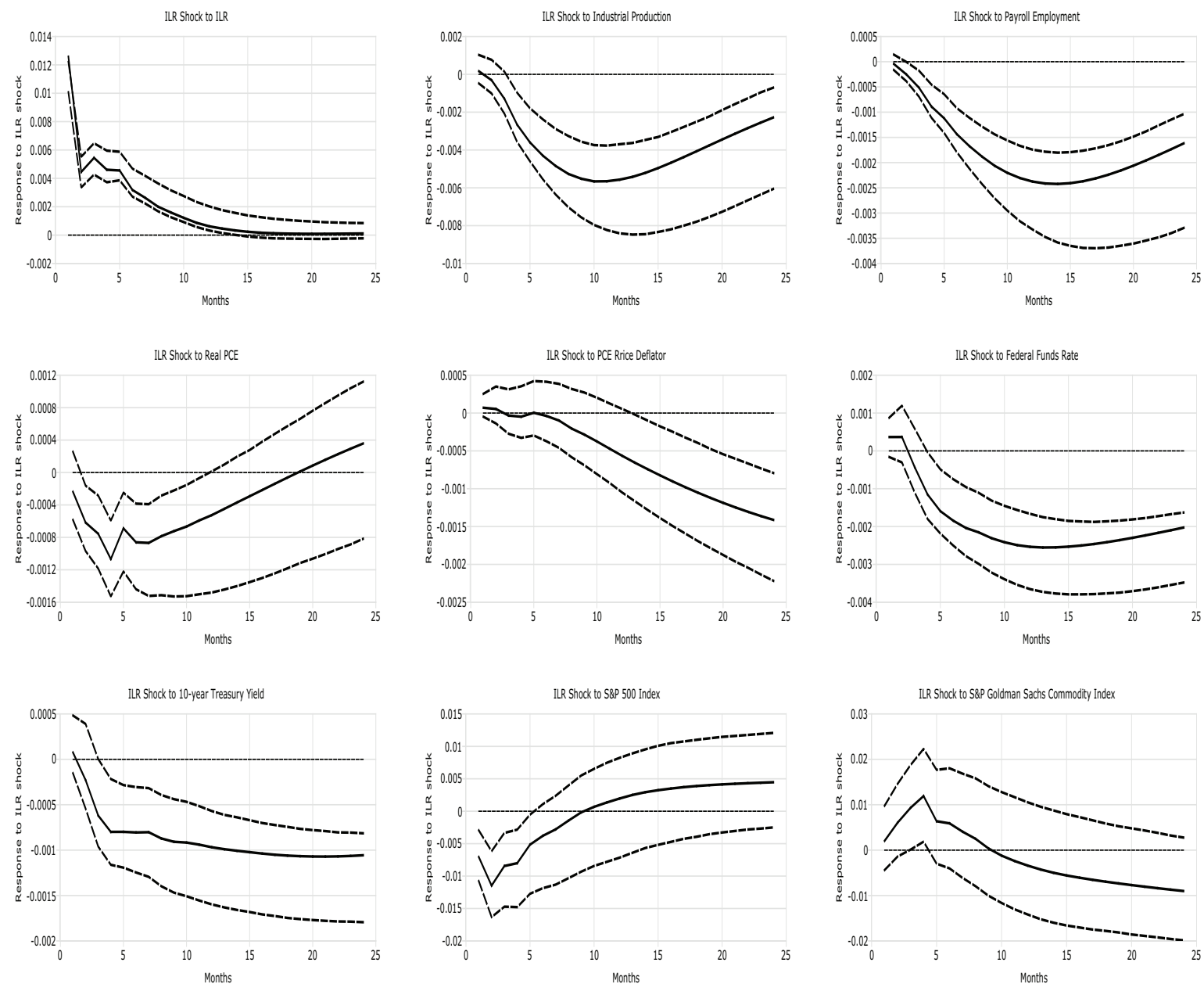

Note: The dashed lines are $90 \%$ bootstrapped confidence intervals. The VAR is identified using the Cholesky decomposition method, and the order of the endogenous variables is (1) $I L R_{t}$; (2) log of manufacturing industrial production index; (3) log of private employment; (4) log of real PCE; (5) log of PCE price deflator; (6) Federal funds rate; (7) nominal 10-year Treasury yield; (8) log of real S\&P 500 Composite Stock Price Index; and (9) log of S\&P GSCI. 
Figure 9: Impulse Response Function of a One-Standard-Deviation Illiquidity Shock from the VAR with Recursive Identification Scheme: $I L R_{t}$ is Ordered after Economic Variables
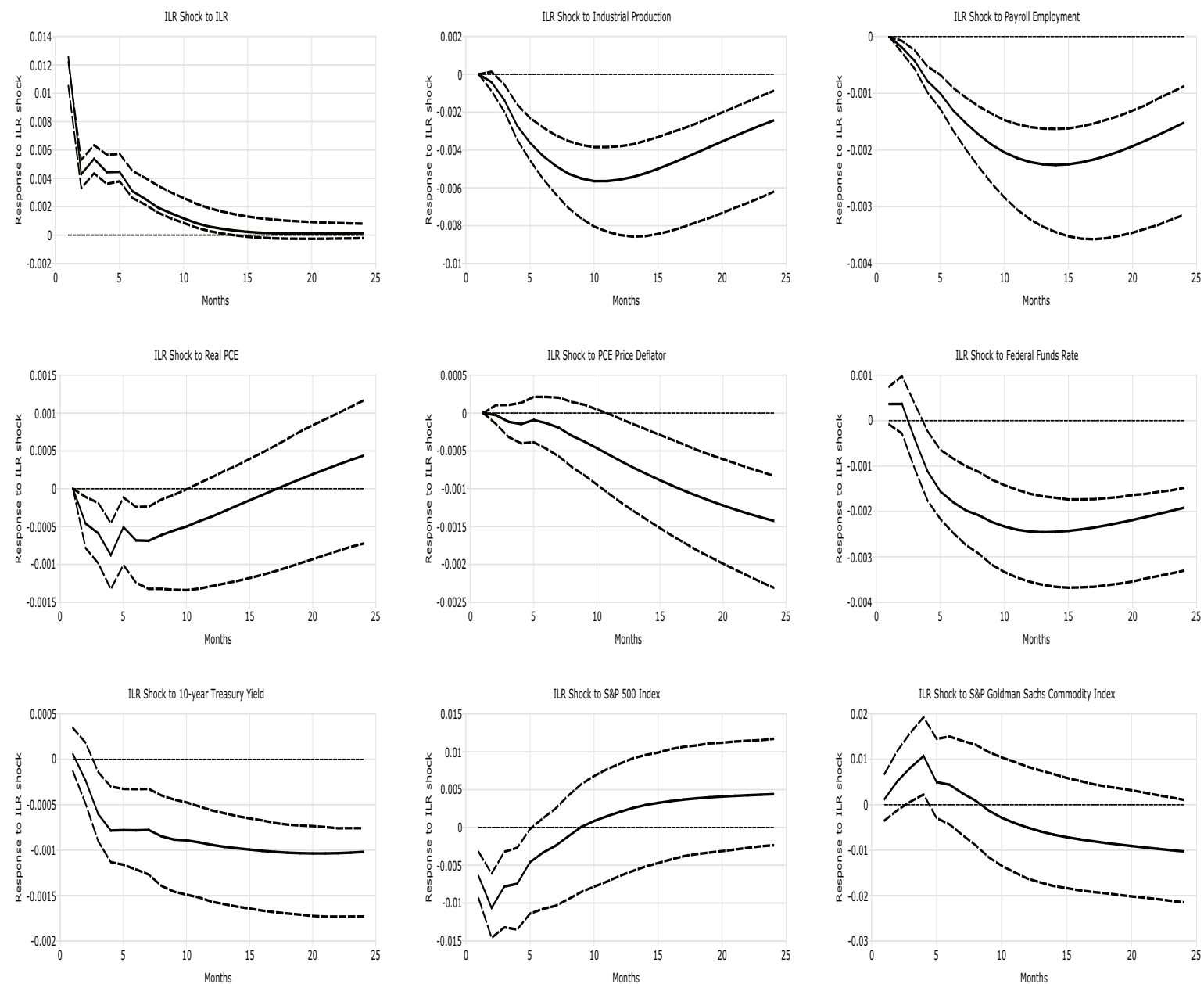

Note: The dashed lines are $90 \%$ bootstrapped confidence intervals. The VAR is identified using the Cholesky decomposition method, and the order of the endogenous variables is (1) log of manufacturing industrial production index; (2) log of private employment; (3) log of real PCE; (4) log of PCE price deflator; (5) ILR ; (6) log of S\&P GSCI; (7) log of real S\&P 500 Composite Stock Price Index; (8) nominal 10-year Treasury yield; and (9) Federal funds rate. 
Figure 10: Impulse Response Function of a One-Standard-Deviation Illiquidity Shock from VAR-8
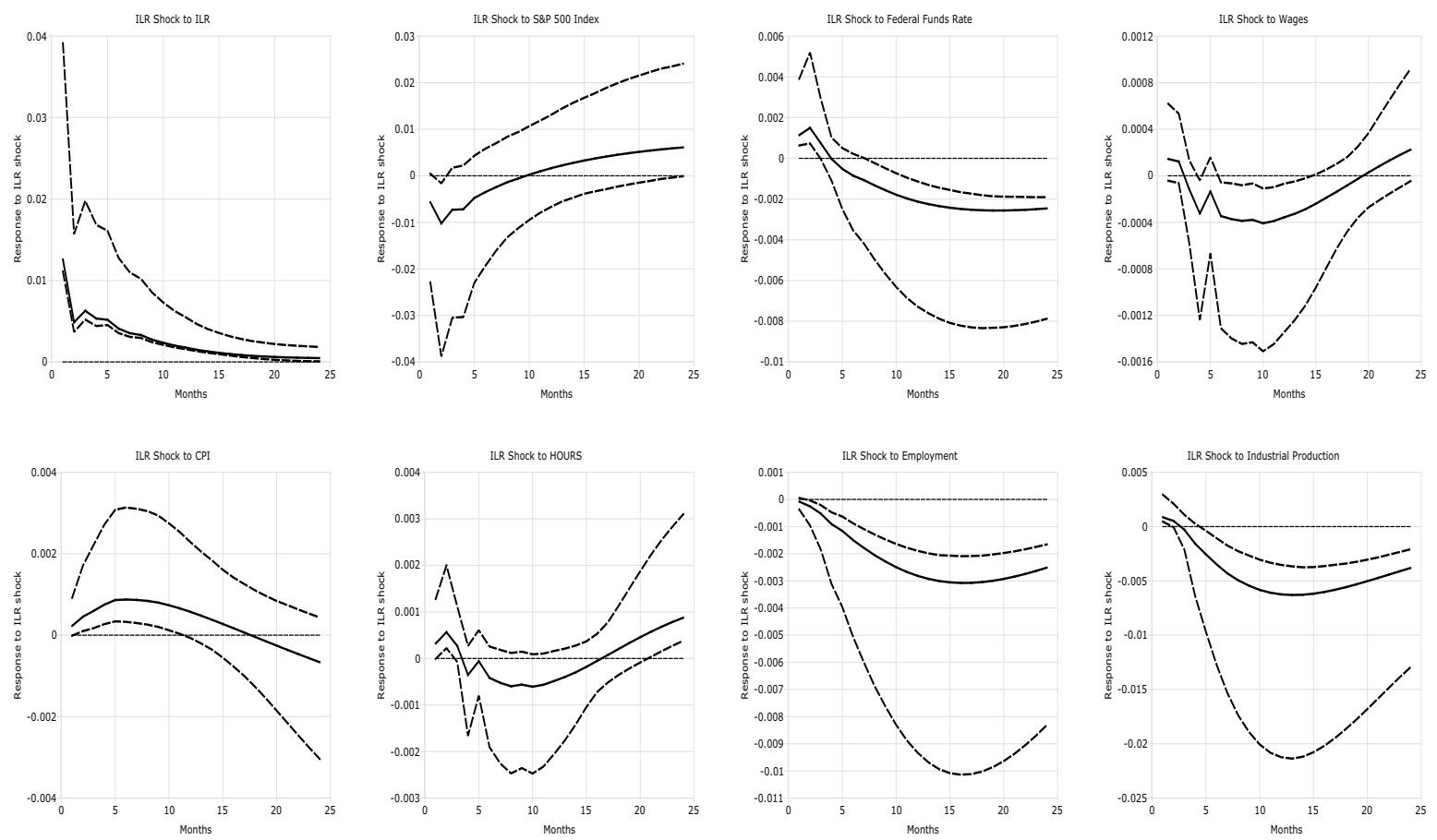

Note: The dashed lines are $90 \%$ bootstrapped confidence intervals. The VAR is identified by the MFEV method with $0<k<180$. 
Figure 11: Impulse Response Function of a One-Standard-Deviation Illiquidity Shock from VAR-12)
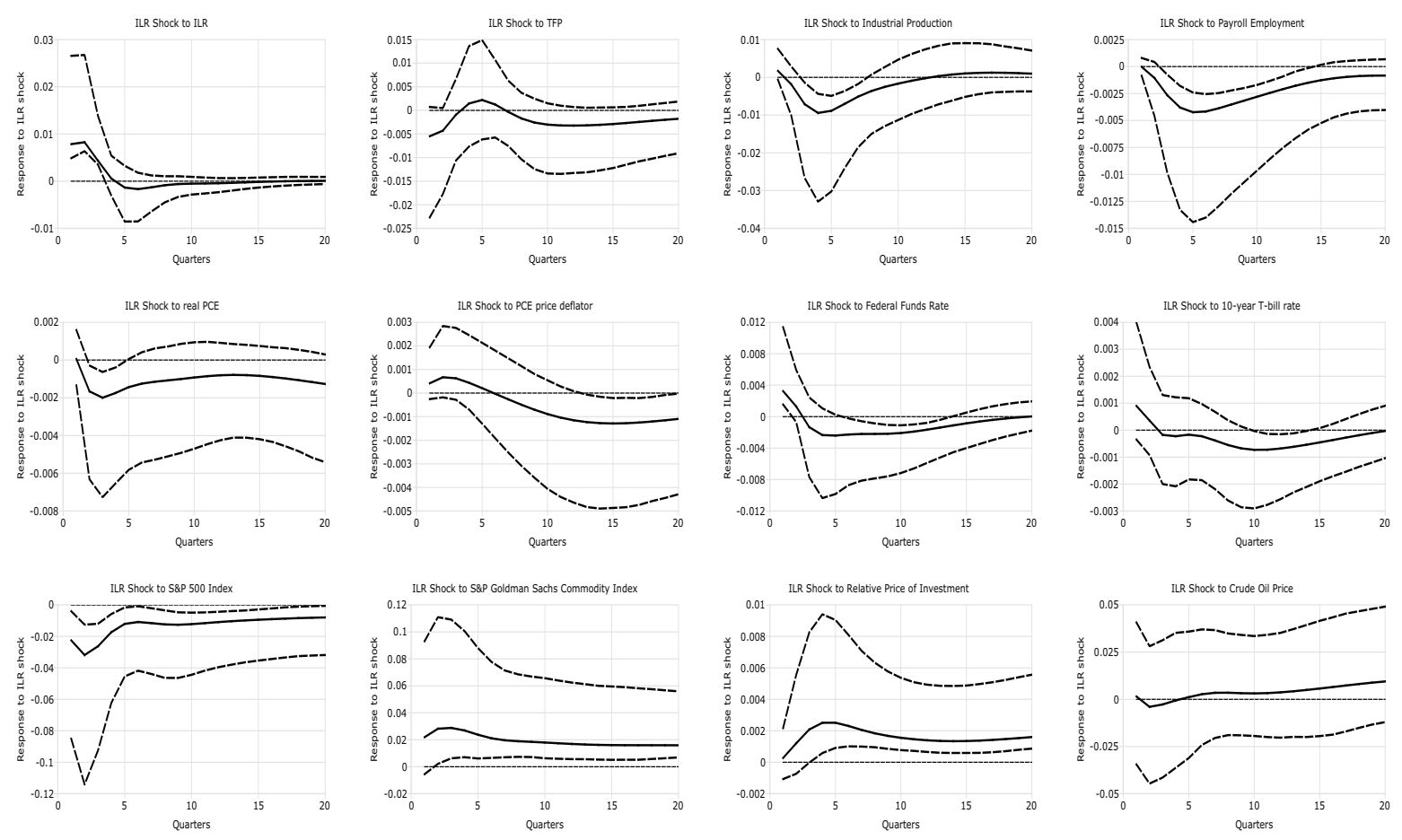

Note: The dashed lines are $90 \%$ bootstrapped confidence intervals. The VAR is identified using the MFEV method with $0<k<40$. 
Figure 12: Impulse Response Function of a One-Standard-Deviation Illiquidity Shock from the VAR with Pastor and Stambaugh (2003)'s Liquidity Factor
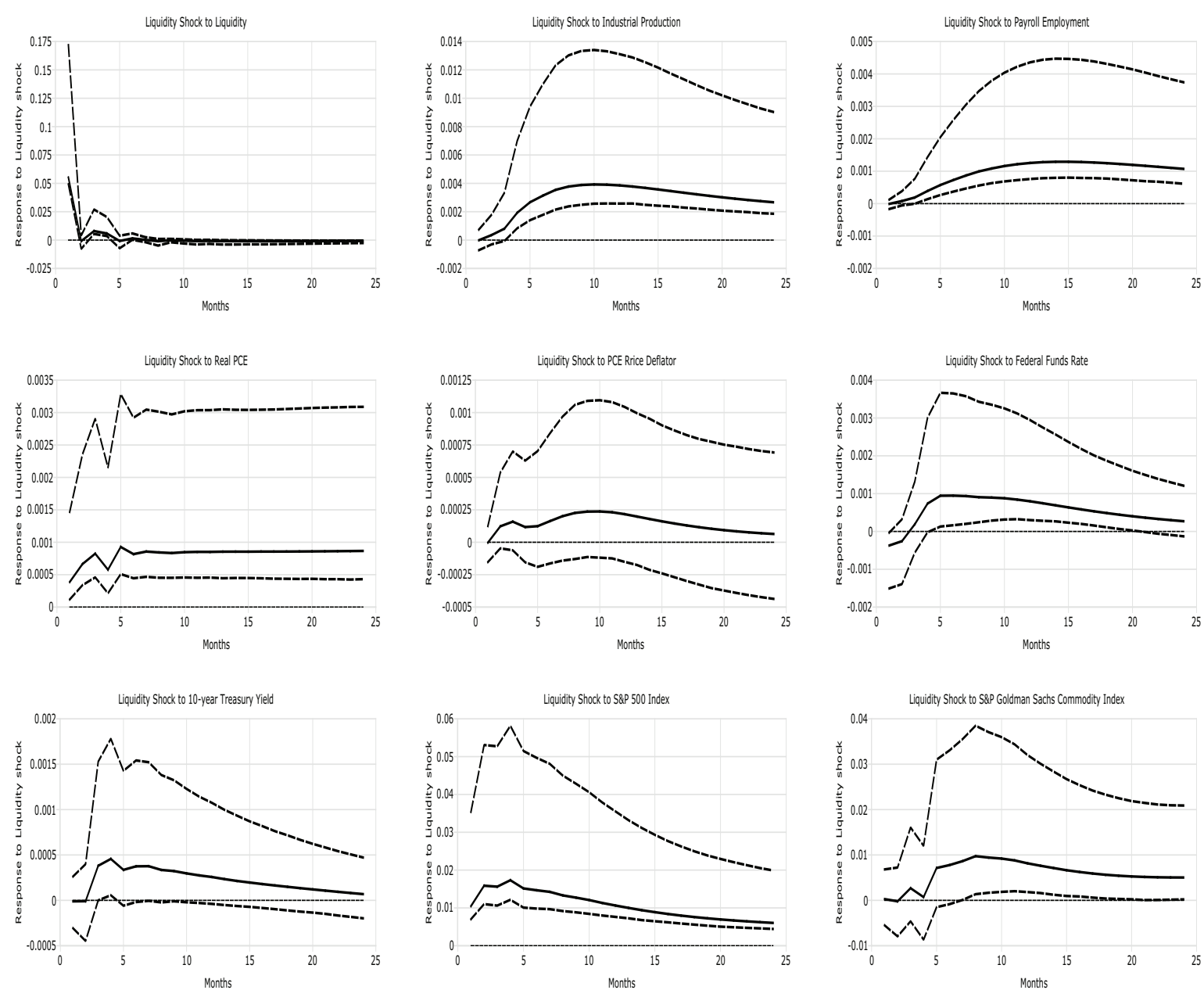

Note: The dashed lines are $90 \%$ bootstrapped confidence intervals. The VAR is identified using the MFEV method with $0<k<180$. 
Figure 13: Impulse Response Function of a One-Standard-Deviation Illiquidity Shock: 1973M1 to $2008 \mathrm{M} 9$
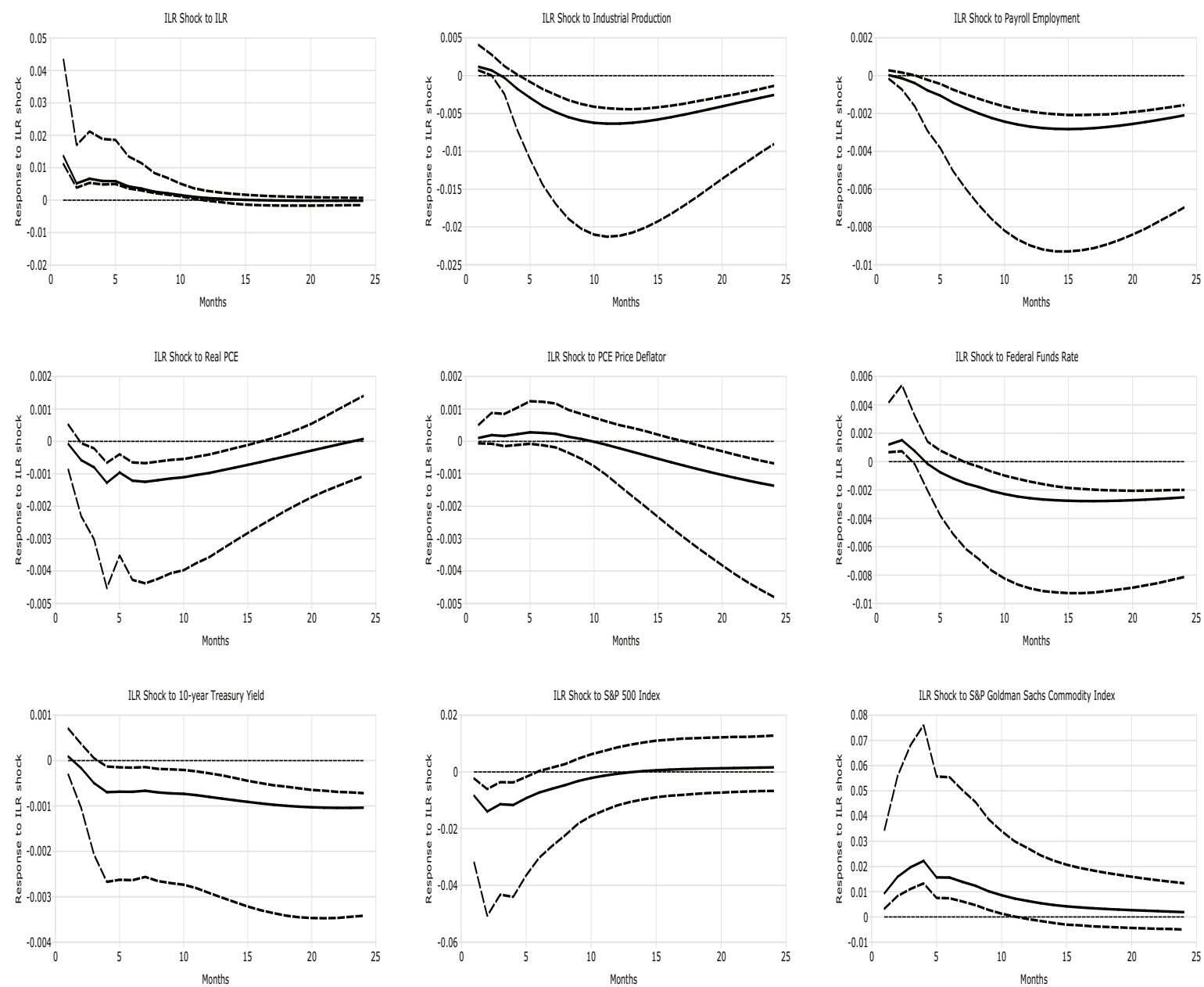

Note: The dashed lines are $90 \%$ bootstrapped confidence intervals. The VAR is identified using the MFEV method with $0<k<180$. 
Figure 14: Impulse Response Function of a One-Standard-Deviation Illiquidity Shock: VAR with the Shadow Rate Proposed by Wu and Xia (2016)
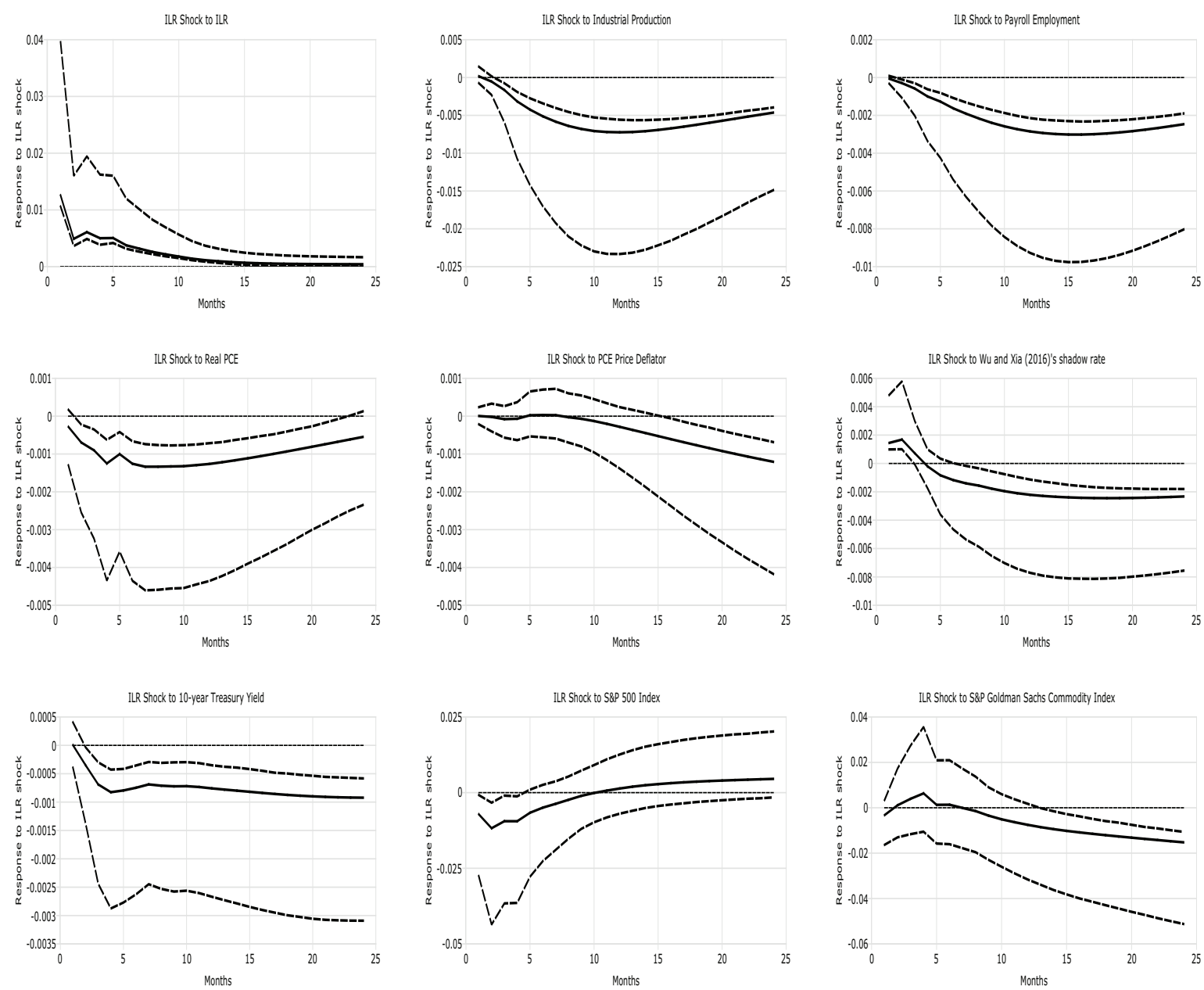

Note: The dashed lines are $90 \%$ bootstrapped confidence intervals. The VAR is identified using the MFEV method with $0<k<180$, with the sample period 1973M1-2015M11. 
Figure 15: Cumulative generalized impulse response of macroeconomic aggregates to onestandard deviation illiquidity shock
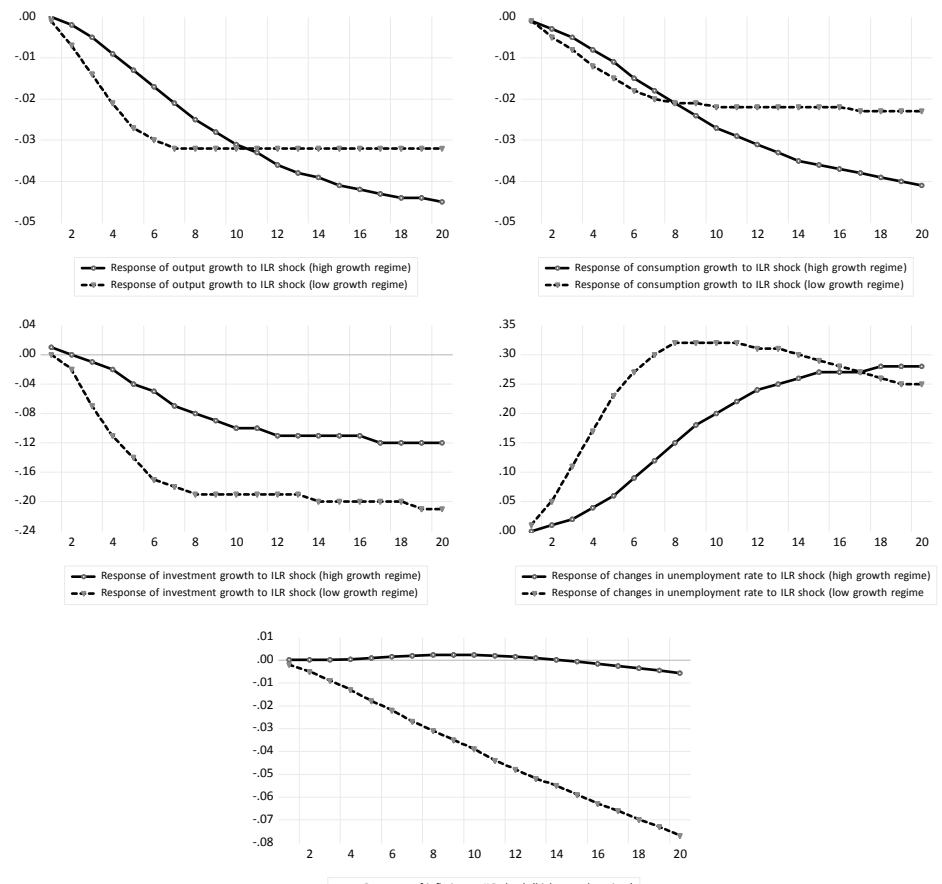

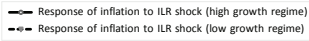

Note: The cumulative generalized impulse response functions are computed from a two-regime TVAR, with a two-quarter moving average of the annual growth rate of $R G D P_{t-1}$ as the threshold variable. The solid lines are responses in the high growth regime, and the dashed lines are responses in the low growth regime. 
Figure 16: Impulse Response Function of a One-Standard-Deviation Financial Shock: EBPUNC Identification Scheme
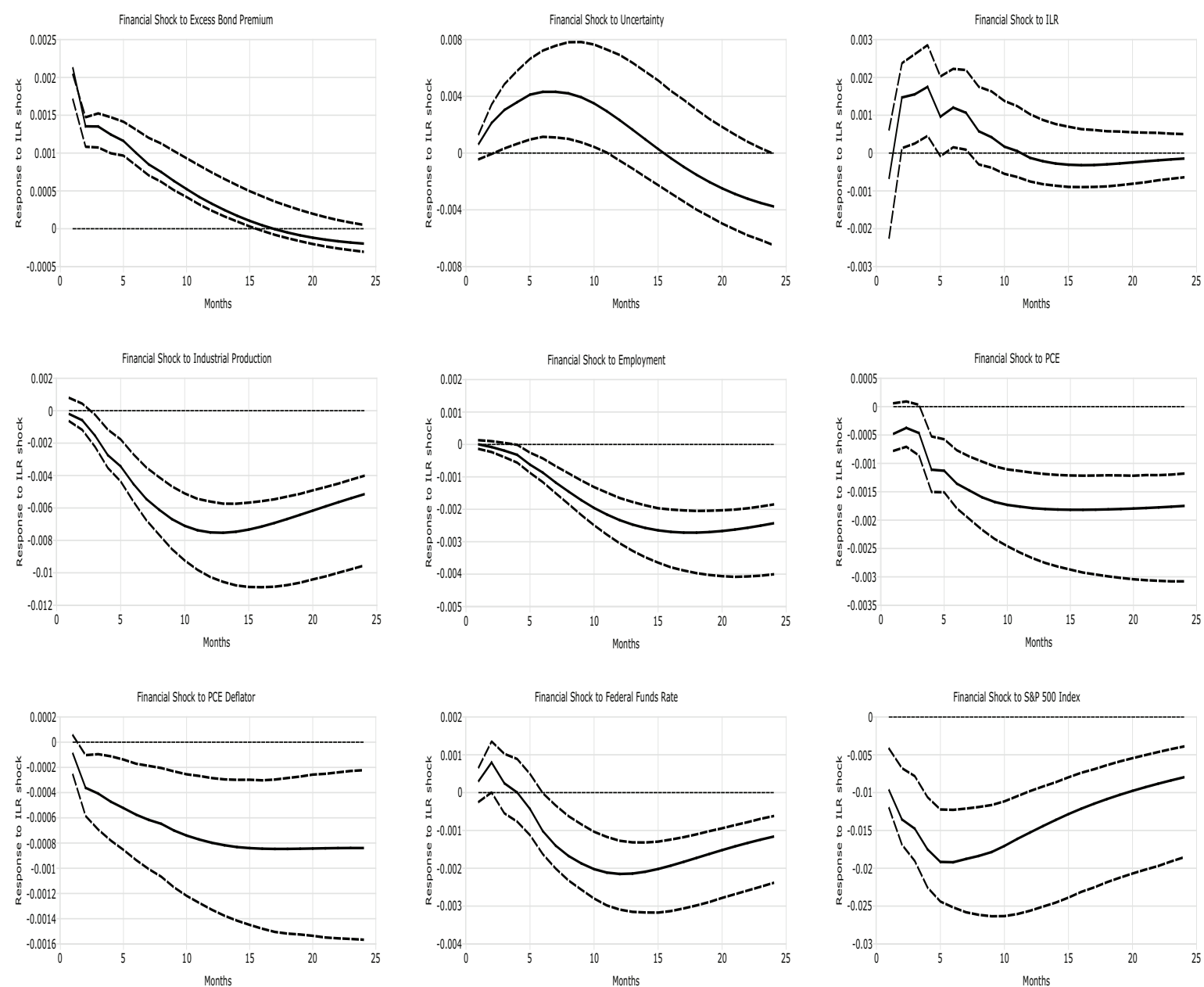

Note: The dashed lines are $90 \%$ bootstrapped confidence intervals. The VAR is identified using the Cholesky decomposition method, and the order of the endogenous variables is (1) excess bond premium; (2) Jurado et al. (2015)'s measure of macroeconomic uncertainty; (3) $I L R_{t}$; (4) log of manufacturing industrial production index; (5) log of private employment; (6) log of real PCE; (7) log of PCE price deflator; (8) Federal funds rate; (9) nominal 10-year Treasury yield; (10) log of real S\&P 500 Composite Stock Price Index; and (11) log of S\&P GSCI. 
Figure 17: Impulse Response Function of a One-Standard-Deviation Uncertainty Shock: EBPUNC Identification Scheme
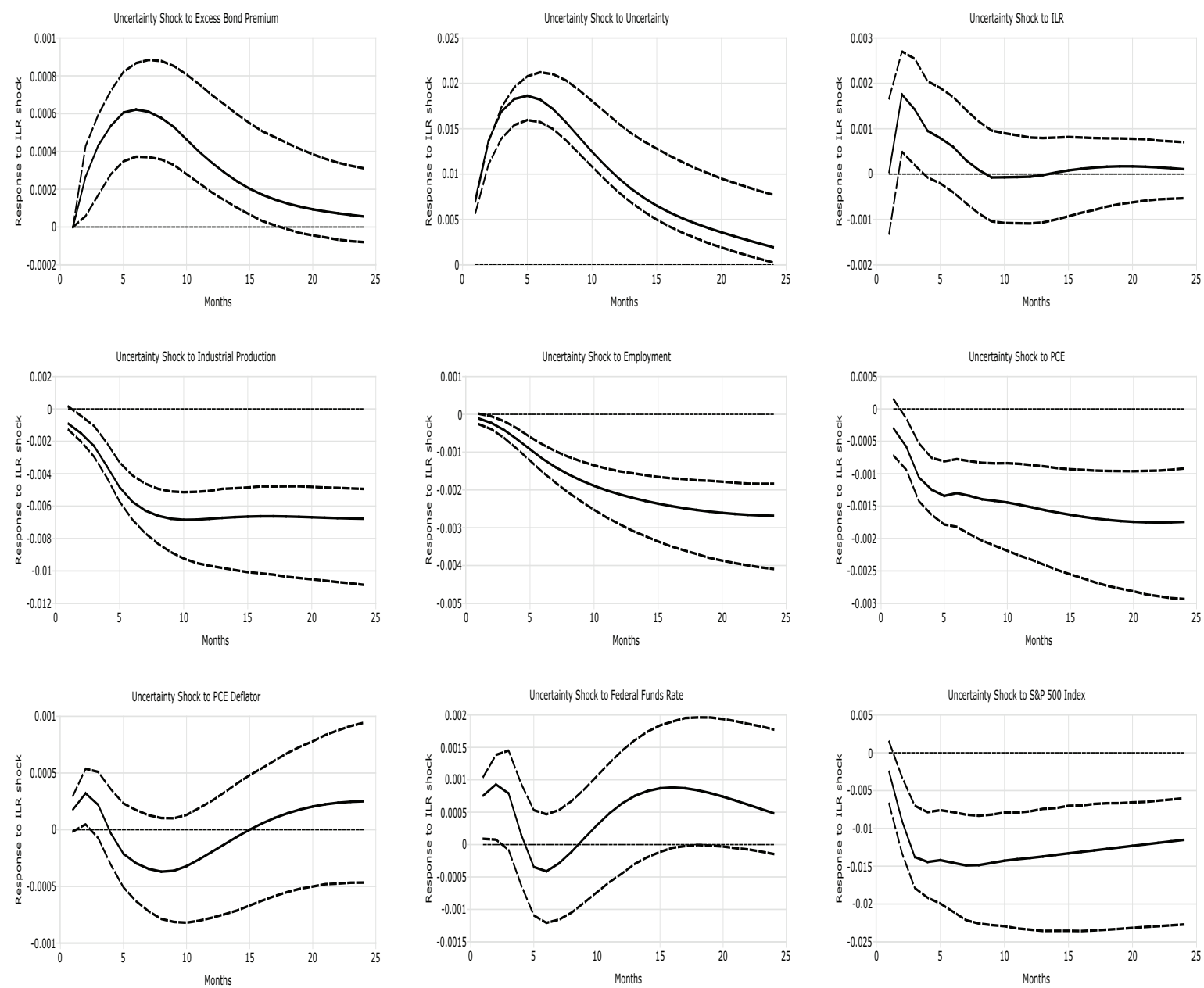

Note: The dashed lines represent $90 \%$ bootstrapped confidence intervals. The VAR is identified using the Cholesky decomposition method, and the order of the endogenous variables is (1) excess bond premium; (2) Jurado et al. (2015)'s measure of macroeconomic uncertainty; (3) $I L R_{t}$; (4) log of manufacturing industrial production index; (5) log of private employment; (6) log of real PCE; (7) log of PCE price deflator; (8) Federal funds rate; (9) nominal 10-year Treasury yield; (10) log of real S\&P 500 Composite Stock Price Index; and (11) log of S\&P GSCI. 
Figure 18: Impulse Response Function of a One-Standard-Deviation Illiquidity Shock: EBPUNC Identification Scheme
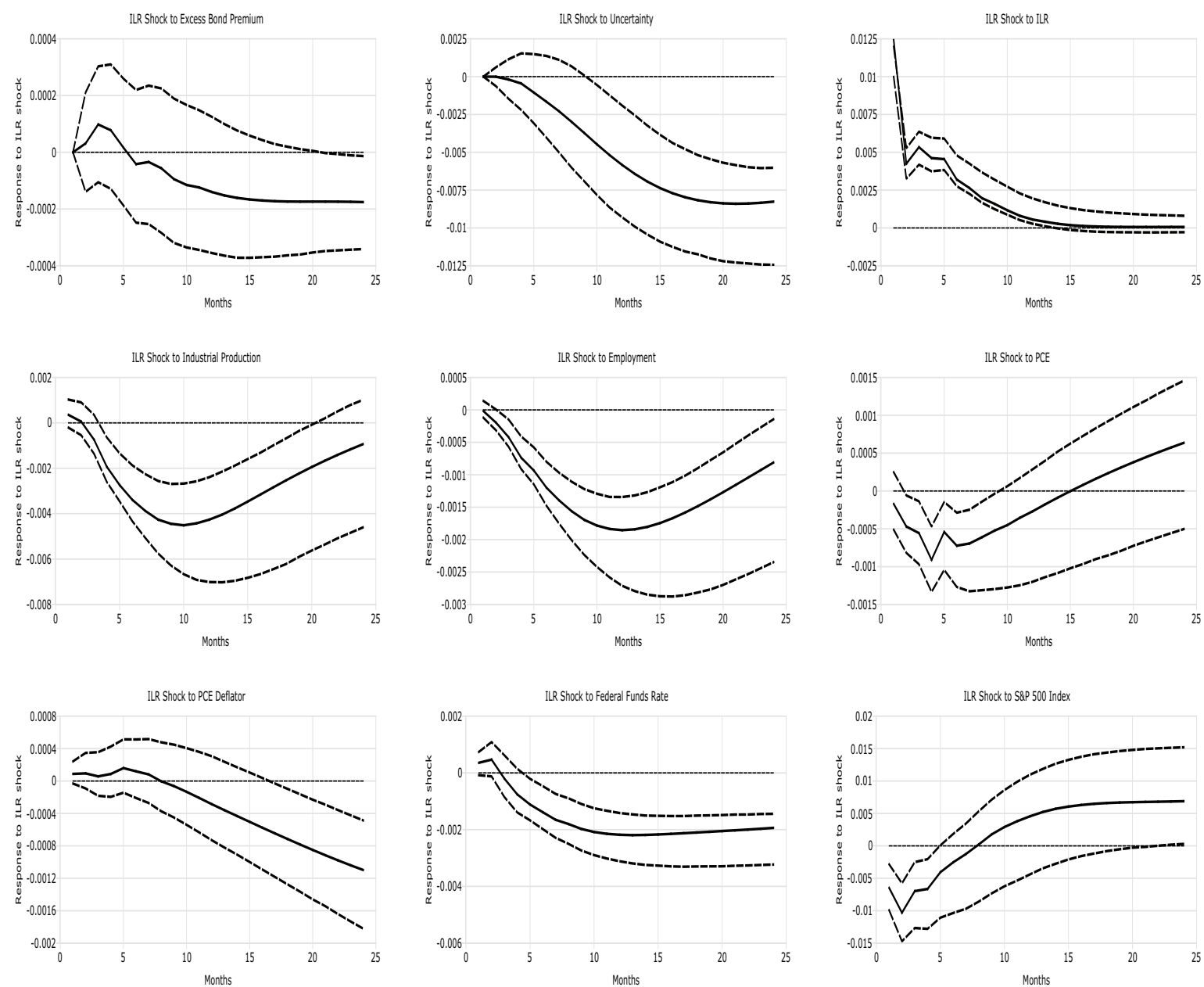

Note: The dashed lines are $90 \%$ bootstrapped confidence intervals. The VAR is identified using the Cholesky decomposition method, and the order of the endogenous variables is (1) excess bond premium; (2) Jurado et al. (2015)'s measure of macroeconomic uncertainty; (3) $I L R_{t}$; (4) log of manufacturing industrial production index; (5) log of private employment; (6) log of real PCE; (7) log of PCE price deflator; (8) Federal funds rate; (9) nominal 10-year Treasury yield; (10) log of real S\&P 500 Composite Stock Price Index; and (11) log of S\&P GSCI. 